\title{
Three-Component Regio- and Stereoselective Polymerizations towards Functional Chalcogen-Rich Polymers with AIE-Activities
}

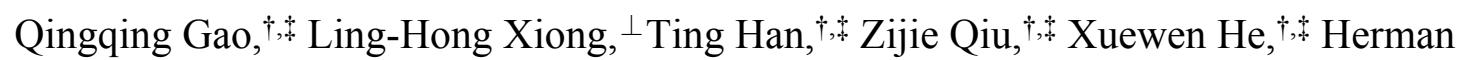

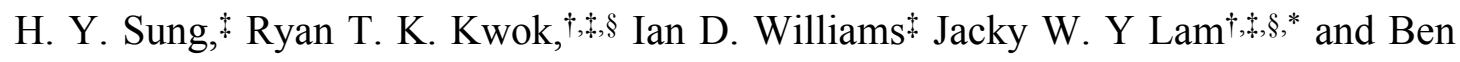
Zhong Tang ${ }^{\dagger}, \$, *$

${ }^{\dagger}$ HKUST-Shenzhen Research Institute, No. 9 Yuexing 1st RD, South Area, Hi-tech Park, Nanshan, Shenzhen 518057, China;

Department of Chemistry, Hong Kong Branch of Chinese National Engineering Research Center for Tissue Restoration and Reconstruction, Division of Life Science, Institute of Advanced Study and Department of Chemical and Biological Engineering;

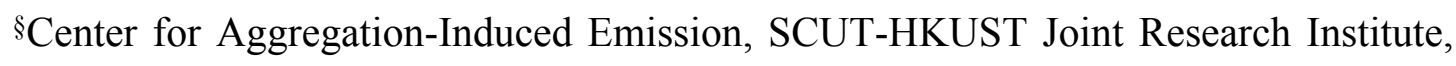
State Key Laboratory of Luminescent Materials and Devices, South China University of Technology, Guangzhou 510640, P. R. China.

${ }^{\perp}$ Shenzhen Center for Disease Control and Prevention, Shenzhen 518055, P. R. China ${ }^{*}$ Corresponding authors: Dr. J. W. Y. Lam and Prof. B. Z. Tang (E-mail: chjacky@ust.hk and tangbenz@ust.hk). Phone: +852-2358-7242 (7375). Fax: +8522358-1594. 


\section{Table of Contents}

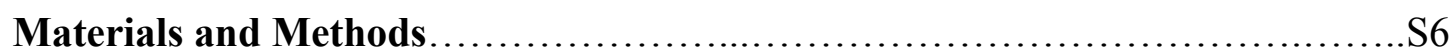

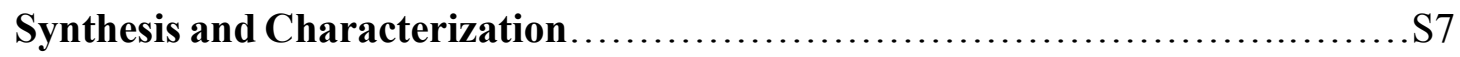

Optimization of Polymerization Conditions ................................... 10

Table S1. Effect of Solvent on the Polymerization of 1a, 2 and $3 a^{a} \ldots \ldots \ldots \ldots \ldots . . . . . . . .11$

Table S2. Solvent Ratio Effect on the Polymerization ${ }^{a}$........................S12

Table S3. Effect of Catalyst on the Polymerization of $1 \mathrm{a}, \mathbf{2}$ and $3 \mathrm{a}^{a} \ldots \ldots \ldots \ldots . . . . . \mathrm{S} 12$

Table S4. Effect of Concentration on the Polymerization 1a, 2 and $3 a^{a}$...........S13

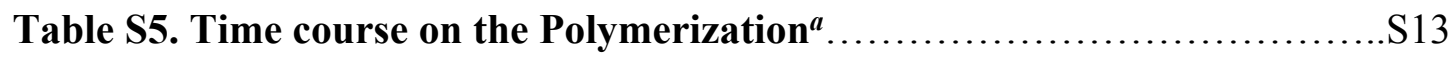

Figure S1. High-resolution mass spectra of model compound $6 \ldots \ldots \ldots \ldots \ldots . . . . . . . . .4$

Figure S2. High-resolution mass spectra of model compound 10................S14

Figure S3. High-resolution mass spectra of model compound $8 \ldots \ldots \ldots \ldots \ldots . . . . . . .515$

Figure S4. High-resolution mass spectra of oxidative model compound 9............S15

Table S6. Summary of Crystal Data of 8 ....................................... 16

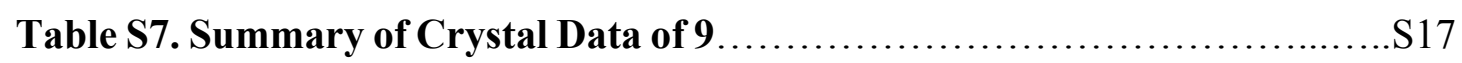

Figure S5. IR spectra of (A) 1a, (B) 2, (C) 3a, (D) 6 and (E) P1a/2/3a .............S18

Figure S6. IR spectra of (A) 1a, (B) 2, (C) 3b and (D) P1a/2/3b................S18

Figure S7. ${ }^{1} \mathrm{H}$ NMR spectra of (A) 1a in chloroform- $d$, (B) 2 in dimethyl sulfoxide- $d_{6}$, (C) 3b and (D) P1a/2/3b in dichloromethane- $d_{2}$. The solvent peaks were marked with

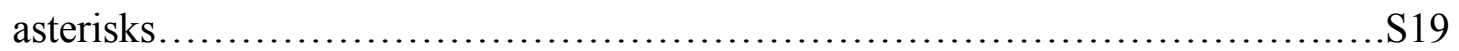

Figure S8. ${ }^{13} \mathrm{C}$ NMR spectra of (A) 1 a in chloroform- $d$, (B) 2 in dimethyl sulfoxide$d_{6}$, (C) $\mathbf{3 b}$ and (D) P1a/2/3b in dichloromethane- $d_{2}$. The solvent peaks were marked with

asterisks.

Figure S9. IR spectra of (A) 1b, (B) 2, (C) 3a and (D) P1b/2/3a .................S20

Figure S10. ${ }^{1} \mathrm{H}$ NMR spectra of (A) $1 \mathrm{~b}$ in chloroform- $d$, (B) 2 in dimethyl sulfoxide$d_{6},(\mathrm{C}) \mathbf{3 a}$ and (D) P1b/2/3a in dichloromethane- $d_{2}$. The solvent peaks were marked

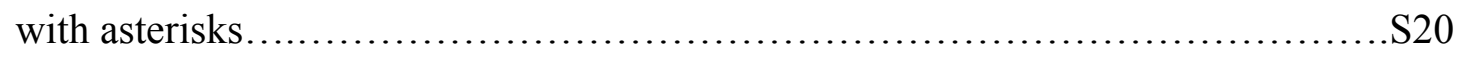

Figure S11. ${ }^{13} \mathrm{C}$ NMR spectra of (A) 1b in chloroform- $d$, (B) 2 in dimethyl sulfoxide$d_{6}$, (C) $\mathbf{3} \mathbf{a}$ and (D) P1b/2/3a in dichloromethane- $d_{2}$. The solvent peaks were marked with asterisks........................................................... 21

Figure S12. IR spectra of (A) 1c, (B) 2, (C) 3a and (D) P1c/2/3a ..................S2 1 
Figure S13. ${ }^{1} \mathrm{H}$ NMR spectra of (A) $1 \mathrm{c}$ in chloroform- $d$, (B) 2 in dimethyl sulfoxide$d_{6},(\mathrm{C}) \mathbf{3 a}$ and (D) P1c/2/3a in dichloromethane- $d_{2}$. The solvent peaks were marked with asterisks S22

Figure S14. ${ }^{13} \mathrm{C}$ NMR spectra of (A) $1 \mathrm{c}$ in chloroform- $d$, (B) 2 in dimethyl sulfoxide$d_{6}$, (C) 3a and (D) P1c/2/3a in dichloromethane- $d_{2}$. The solvent peaks were marked with asterisks S22

Figure S15. IR spectra of (A) 1b, (B) 2, (C) 3b and (D) P1b/2/3b. S23 Figure S16. ${ }^{1} \mathrm{H}$ NMR spectra of (A) $1 \mathbf{b}$ and (D) P1b/2/3b in chloroform- $d$, (B) 2 in dimethyl sulfoxide- $d_{6}$, (C) $\mathbf{3 b}$ in dichloromethane- $d_{2}$. The solvent peaks were marked with asterisks. S23

Figure S17. IR spectra of (A) 1c, (B) 2, (C) 3 b and (D) P1c/2/3b. S24

Figure S18. ${ }^{1} \mathrm{H}$ NMR spectra of (A) $1 \mathrm{c}$ in chloroform-d, (B) 2 in dimethyl sulfoxide$d_{6},(\mathrm{C}) \mathbf{3 b}$ and (D) P1c/2/3b in dichloromethane- $d_{2}$. The solvent peaks were marked with asterisks S24

Figure S19. ${ }^{13} \mathrm{C}$ NMR spectra of (A) $1 \mathrm{c}$ in chloroform- $d$, (B) 2 in dimethyl sulfoxide$d_{6},(\mathrm{C}) \mathbf{3 b}$ and (D) P1c/2/3b in dichloromethane- $d_{2}$. The solvent peaks were marked with asterisks S25

Figure S20. IR spectra of (A) 1d, (B) 2, (C) 3b and (D) P1d/2/3b S25

Figure S21. ${ }^{1} \mathrm{H}$ NMR spectra of (A) 1d in chloroform- $d$, (B) 2 in dimethyl sulfoxide$d_{6}$, (C) 3b and (D) P1d/2/3b in dichloromethane- $d_{2}$. The solvent peaks were marked with asterisks S26

Figure S22. ${ }^{13} \mathrm{C}$ NMR spectra of (A) $1 \mathbf{d}$ in chloroform- $d$, (B) 2 in dimethyl sulfoxide$d_{6}$, (C) $\mathbf{3 b}$ and (D) P1d/2/3b in dichloromethane- $d_{2}$. The solvent peaks were marked with asterisks S26

Figure S23. IR spectra of (A) 1a, (B) 2, (C) 3a, (D) 3c and (E) P1a/2/3ac. S27

Figure S24. ${ }^{1} \mathrm{H}$ NMR spectra of (A) 1a and (C) 3a in dichloromethane- $d_{2}$, (B) 2 in dimethyl sulfoxide- $d_{6}$, (D) 3c and (E) P1a/2/3ac in chloroform- $d$. The solvent peaks were marked with asterisks. S27 Figure S25. ${ }^{13} \mathrm{C}$ NMR spectra of (A) 1 a and (C) 3a in dichloromethane- $d_{2}$, (B) 2 in dimethyl sulfoxide- $d_{6}$, (D) 3c and (E) P1a/2/3ac in chloroform- $d$. The solvent peaks were marked with asterisks. $\mathrm{S} 28$ Figure S26. (A) TGA and (B) DSC thermograms of P1/2/3 recorded under nitrogen at a heating rate of $10^{\circ} \mathrm{C} / \mathrm{min}$. S28 
Figure S27. Absorption spectras of (A) P1/2/3 (B) and P1a/2/3a, OP1a/2/3a, 6 and 10

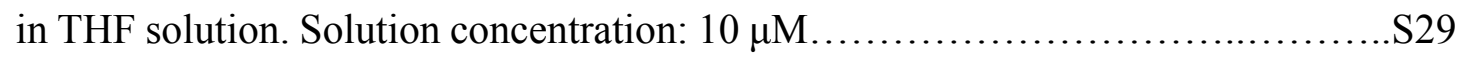
Figure S28. (A) Fluorescent photographs of P1a/2/3a in THF/water mixtures with different water fractions $\left(f_{w}\right)$ taken under $365 \mathrm{~nm}$ UV irradiation from a hand-held UV lamp. (B) The emission spectra of P1a/2/3a in $\mathrm{THF} /$ water mixtures with different water fractions $\left(f_{w}\right)$. Solution concentration: $10 \mu \mathrm{M}$; excitation wavelength: $350 \mathrm{~nm}$. (C) The plot of $\alpha_{\mathrm{AIE}}$ versus the water fraction of the THF/water mixtures of $\mathrm{P} 1 \mathbf{a} / \mathbf{2} / \mathbf{3 a}$. .S29

Figure S29. Emission spectra of $\mathrm{P} \mathbf{1 a} / \mathbf{2} / \mathbf{3 b}$ in THF solution and $\mathrm{THF} /$ water mixture with $90 \%$ water fraction. Solution concentration: $10 \mu \mathrm{M}$; excitation wavelength: 350 $\mathrm{nm}$. Inset: fluorescent photographs of $\mathrm{P} \mathbf{1} \mathbf{a} / \mathbf{2} / \mathbf{3} \mathbf{b}$ in THF solution and THF/water mixture with $90 \%$ water fraction taken under $365 \mathrm{~nm} \mathrm{UV}$ illumination from a hand-held UV lamp. S30

Figure S30. (A) Fluorescent photographs of P1a/2/3ac in THF/water mixtures with different water fractions $\left(f_{w}\right)$ taken under $365 \mathrm{~nm}$ UV irradiation from a hand-held UV lamp. (B) The emission spectra of P1a/2/3ac in THF/water mixtures with different water fractions $\left(f_{w}\right)$. Solution concentration: $10 \mu \mathrm{M}$; excitation wavelength: $350 \mathrm{~nm}$. (C) The plot of $\alpha_{\mathrm{AIE}}$ versus the water fraction of the THF/water mixtures of $\mathrm{P} 1 \mathrm{a} / \mathbf{2} / \mathbf{3 a c}$ S30

Figure S31. (A) Emission spectra of model compound 6 in THF/water mixtures with different water fractions $\left(f_{w}\right)$. Solution concentration: $10 \mu \mathrm{M}$; excitation wavelength: $330 \mathrm{~nm}$. (B) The plot of $\alpha_{\mathrm{AIE}}$ versus the water fraction of the THF/water mixtures of 6. Inset: fluorescent photographs of $\mathbf{6}$ in THF solution and THF/water mixture with $90 \%$ water fraction taken under $365 \mathrm{~nm}$ UV illumination from a hand-held UV lamp.

Figure S32. Emission spectra of $\mathbf{1 0}$ in THF/water mixtures with different water fractions $\left(f_{w}\right)$. Solution concentration: $10 \mu \mathrm{M}$; excitation wavelength: $330 \mathrm{~nm}$. (B) The plot of $\alpha_{\mathrm{AIE}}$ versus the water fraction of the THF/water mixtures of 10. Inset: fluorescent photographs of $\mathbf{1 0}$ in THF solution and THF/water mixture with 99\% water fraction taken under $365 \mathrm{~nm}$ UV illumination from a hand-held UV lamp..................S31

Figure S33. Mechanism of copper-catalyzed reaction of diphenyl diselenide, benzenesulfonyl hydrazide and terminal alkyne............................. 32

Figure S34. MTT assay on HeLa cells incubated with P1a/2/3a and OP1a/2/3a at different concentrations from 0 to $100 \mu \mathrm{M}$ for $24 \mathrm{~h}$. S32 
Table S8. Quantum yields of polymers solids..............................S32

Figure S35. ${ }^{1} \mathrm{H}$ NMR spectra of the P1a/2a/3a before and after light irradiation.......S33

Figure S36. UV spectra of the THF solutions of P1a/2/3a before and after light

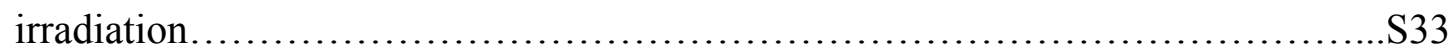

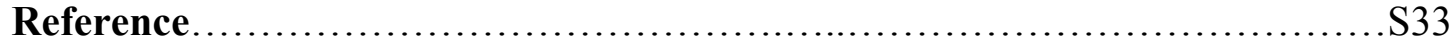




\section{Materials and Methods}

Tetrakis(acetonitrile)copper(I) hexafluorophosphate, potassium persulfate, monomer 2 4,4'-oxybis(benzenesulfonyl hydrazide), hydrogen peroxide, 3a-c (diphenyl diselenide, diphenyl ditelluride and diphenyl disulfide), phenyl acetylene 7 and benzenesulfonyl hydrazide 5 were purchased from $\mathrm{JK}$ and used without further purification. All the organic solvents were distilled prior to use. Monomers 1a-d were prepared according to the literature. ${ }^{1-3}$

Weight average molecular weight $\left(M_{w}\right)$ and polydispersity index (PDI) of the polymer samples were measured at $40{ }^{\circ} \mathrm{C}$ on a Waters gel permeation chromatography (GPC) system equipped with a $486 \mathrm{UV}$-vis detector and a temperature controller. The eluent was THF and the flow rate was $1 \mathrm{~mL} \cdot \mathrm{min}^{-1}$. The polymers were dissolved in THF and filtered through a $0.45 \mu \mathrm{m}$ PTFE filter before injection to the GPC system. The IR spectra were recorded on a Perkin-Elmer 16 PC FTIR spectrophotometer. ${ }^{1} \mathrm{H}$ NMR and ${ }^{13} \mathrm{C}$ NMR spectra were recorded on a Bruker AV 400 spectrometer in deuterated solvents with tetramethylsilane (TMS; $\delta=0)$ as internal reference. Highresolution mass spectra (HRMS) were recorded on a GCT premier CAB048 mass spectrometer operated in MALDI-TOF mode. UV spectra and photoluminescence (PL) spectra were recorded on a Milton Ray Spectronic 3000 Array spectrophotometer and Perkin-Elmer LS 55 spectrophotometer, respectively. A TA TGA Q5000 analyzer and TA Instruments DSC Q1000 were employed to perform the thermogravimetric (TGA) and differential scanning calorimetry (DSC) analysis under nitrogen at a heating rate of $10^{\circ} \mathrm{C} \cdot \mathrm{min}^{-1}$. The photo patterns of the polymer films were prepared by UV irradiation through copper masks from a Driel UV lamp. Detailed procedures could be found in our previous publications. ${ }^{3}$

MTT assay for cell viability measurement. MDCK cells were obtained from Shenzhen Center for Disease and Prevention. Cells were grown in DMEM supplemented with $10 \%$ fetal bovine serum, 1\% penicillinstreptomycin solution (10,000 units of penicillin and $10 \mathrm{mg}$ of streptomycin in $1 \times \mathrm{PBS})$ in a humidified incubator at $37{ }^{\circ} \mathrm{C}$ containing $\mathrm{CO}_{2}(5 \%) .100 \mu \mathrm{L}$ of cell solution/well was seeded (4×104 cells) into a 96-well plate (Corning) and incubated for $24 \mathrm{~h}$. These cells were washed twice with DMEM and then treated with the range of OP1a/2/3a and P1a/2/3a with a concentration from 0 to $100 \mu \mathrm{M}$ for $24 \mathrm{~h}$, respectively. After $24 \mathrm{~h}$ treatment of OP1a/2/3a and P1a/2/3a to MDCK cells, respectively, cells were incubated with 0.5 
$\mathrm{mg} / \mathrm{mL}$ of MTT $(100 \mu \mathrm{L})$ for $4 \mathrm{~h}$ and then dissolved by DMSO $(200 \mu \mathrm{L})$. The absorbance value was recorded at $570 \mathrm{~nm}$ using an Infinite M1000 plate reader (Tecan).

Live cell imaging. $1 \times 10^{5} \mathrm{HeLa}$ cells were seeded on the $15 \mathrm{~mm}$ confocal glass dish and incubated for $24 \mathrm{~h}$. After that, OP1a/2/3a and P1a/2/3a were added into the medium with the final concentration of $10 \mu \mathrm{M}$ and incubated for $1 \mathrm{~h}$ at $37^{\circ} \mathrm{C}$, respectively. Then cells were washed three times with Hank's balanced salt solution (HBSS) and incubated with SYTO 59 (ThermoFisher, final concentration: $1 \mu \mathrm{M}$ ) for $30 \mathrm{~min}$ at $37{ }^{\circ} \mathrm{C}$. The cells were washed three times with HBSS and imaged by laser confocal microscopy (Leica TCS SP5) with 63X objective lens. Excitation and emission filters were as follows: OP1a/2/3a and P1a/2/3a: $405 \mathrm{~nm}$ excitation, 430-560 nm emission; SYTO 59: $568 \mathrm{~nm}$ excitation, 620-680 $\mathrm{nm}$ emission.

\section{Synthesis and Characterizations}

Polymer Synthesis. All the polymerization reactions were performed under nitrogen using a standard Schlenk technique. A typical polymerization procedure was shown below using P1a/2/3a as an example. $0.2 \mathrm{mmol}$ of TPE-diyne 1a, $0.2 \mathrm{mmol}$ of 2, 0.2 mmol of 3a, $0.02 \mathrm{mmol}$ of $\mathrm{Cu}(\mathrm{MeCN})_{4} \mathrm{PF}_{6}$ and $0.8 \mathrm{mmol}$ of potassium persulfate were added into a $10 \mathrm{~mL}$ Schlenk tube. Then $0.5 \mathrm{~mL}$ of DMF and $0.5 \mathrm{~mL}$ of acetonitrile were injected into the tube slowly. The resulting solution was stirred at room temperature for $3 \mathrm{~h}$ under the protection of nitrogen. To remove the catalyst residue and insoluble substrates, the resulting solution was added through a column of neutral aluminium oxide drop by drop into $200 \mathrm{~mL}$ hexane/DCM mixed solvent (v/v = 10:1). Afterwards, the precipitates were collected and dried in vacuum to a constant weight. Pale yellow powder was obtained in high yield (Table S5, entry 4). Structural characterization information for all polymers was shown as below:

Structural Characterization Data for P1a/2/3a: Pale yellow powder; yield: 92.3\%; $M_{w}: 12,600 ; M_{w} / M_{n}: 1.8$. IR (film), $v\left(\mathrm{~cm}^{-1}\right): 3059,1580,1485,1439,1327,1294,1240$, 1140, 1084, 1020, 818, 741. ${ }^{1} \mathrm{H}$ NMR $\left(\mathrm{CD}_{2} \mathrm{Cl}_{2}, 400 \mathrm{MHz}\right), \delta$ (ppm): 7.53, 7.43, 7.38, $7.23,7.14,7.12,7.08,7.03,7.02,6.99,6.96,6.95,6.90,6.87,6.18,6.15 .{ }^{13} \mathrm{C} \mathrm{NMR}$ $\left(\mathrm{CD}_{2} \mathrm{Cl}_{2}, 100 \mathrm{MHz}\right), \delta$ (ppm): 160.29, 158.77, 158.12, 145.44, 143.79, 143.55, 141.68, $141.50,138.28,137.08,133.64$, 132.70, 132.16, 131.94, 131.76, 131.65, 131.31, $131.16,130.64,130.54,129.86,129.74,128.61,128.38,128.05,127.49,127.23$, $126.22,119.88$. 
Structural Characterization Data for P1b/2/3a: White powder; yield: $64.1 \% ; M_{w}$ : 8,200; $M_{w} / M_{n}:$ 1.4. IR (film), $v$ (cm-1): 3047, 1580, 1485, 1439, 1319, 1294, 1244, 1144 , 1084, 1003, 897, 826, 741, 689, 555. ${ }^{1} \mathrm{H}$ NMR $\left(\mathrm{CD}_{2} \mathrm{Cl}_{2}, 400 \mathrm{MHz}\right), \delta$ (ppm): 7.60, 7.54, 7.52, 7.51, 7.49, 7.46, 7.44, 7.41, 7.39, 7.35, 7.34, 6.94, 6.92, 6.17. ${ }^{13} \mathrm{C} \mathrm{NMR}\left(\mathrm{CD}_{2} \mathrm{Cl}_{2}\right.$, $100 \mathrm{MHz}), \delta$ (ppm): 159.64, 156.82, 156.79, 141.10, 137.34, 136.63, 136.49, 134.44, $130.29,130.16,129.92,129.33,129.24,126.45,119.25,119.02$.

Structural Characterization Data for P1c/2/3a: White powder; yield: $81.4 \% ; M_{w}$ : 10,800; $M_{w} / M_{n}$ : 1.4. IR (film), $v\left(\mathrm{~cm}^{-1}\right): 3063,1580,1508,1485,1321,1298,1248$, 1144, 1086, 833, 743, 692, 555. ${ }^{1} \mathrm{H}$ NMR $\left(\mathrm{CD}_{2} \mathrm{Cl}_{2}, 400 \mathrm{MHz}\right), \delta$ (ppm): 8.20, 8.08, 7.84, 7.82, 7.59, 7.58, 7.48, 7.46, 7.44, 7.23, 7.21, 7.17, 7.15, 6.93, 6.90, 6.56, 6.54, 5.76, 5.45, 4.30, 4.09. ${ }^{13} \mathrm{C} \mathrm{NMR}\left(\mathrm{CD}_{2} \mathrm{Cl}_{2}, 100 \mathrm{MHz}\right), \delta(\mathrm{ppm}): 159.90,155.80,144.38$, $137.02,130.31,130.21,129.68,127.76,1143.33,67.16,47.10,30.72$.

Structural Characterization Data for P1a/2/3b: Pale yellow powder; yield: $87.1 \%$; $M_{w}: 20,800 ; M_{w} / M_{n}: 2.7$. IR (film), $v\left(\mathrm{~cm}^{-1}\right): 3059,1578,1485,1327,1296,1244,1144$, 1086, 737, 700. ${ }^{1} \mathrm{H}$ NMR $\left(\mathrm{CD}_{2} \mathrm{Cl}_{2}, 400 \mathrm{MHz}\right), \delta$ (ppm): 7.75, 7.45, 7.44, 7.43, 7.31, 7.11, 7.10, 7.09, 7.01, 7.00, 6.92, 6.48, 6.46, 6.45, 6.40. ${ }^{13} \mathrm{C} \mathrm{NMR}\left(\mathrm{CD}_{2} \mathrm{Cl}_{2}, 100 \mathrm{MHz}\right)$, $\delta(\mathrm{ppm}): 146.36,145.92,144.32,144.12,143.98,143.20,143.05,140.96,140.80$, $137.61,137.49$, 137.33, 135.74, 135.64, 132.24, 132.08, 131.91, 131.75, 131.57, $131.31,131.17,131.10,130.92,130.74,130.55,130.13,129.79,127.96,126.98$, $119.38,119.25,114.89$.

Structural Characterization Data for P1b/2/3b: Yellow powder; yield: $44.3 \% ; M_{w}$ : 6,500; $M_{w} / M_{n}: 1.2$. IR (film), $v\left(\mathrm{~cm}^{-1}\right): 3065,3047,1641,1618,1580,1487,1435,1402$, 1385, 1319, 1296, 1242, 1163, 1136, 1082, 1016, 1005, 885, 826, 773, 737, 690, 548. ${ }^{1} \mathrm{H} \mathrm{NMR}\left(\mathrm{CDCl}_{3}, 400 \mathrm{MHz}\right), \delta(\mathrm{ppm}): 7.93,7.92,7.50,7.48,7.43,7.41,7.39,7.38$, $7.35,7.24,7.22,7.12,7.10,6.63,6.62,6.60,6.55$. Due to its poor solubility, ${ }^{13} \mathrm{C}$ NMR spectra of $\mathrm{P} \mathbf{1 b} / \mathbf{2} / \mathbf{3 b}$ was not obtained.

Structural Characterization Data for P1c/2/3b: White powder; yield: $79.7 \% ; M_{w}$ : 13,800; $M_{w} / M_{n}: 2.0$. IR (film), v ( $\left.\mathrm{cm}^{-1}\right): 3065,2968,1609,1580,1510,1487,1435$, $1385,1317,1300,1246,1184,1146,1086,1036,1015,874,833,739,694,555 .{ }^{1} \mathrm{H}$ NMR $\left(\mathrm{CD}_{2} \mathrm{Cl}_{2}, 400 \mathrm{MHz}\right), \delta(\mathrm{ppm}): 8.01,7.92,7.80,7.64,7.35,7.19,7.16,7.05,6.97$, 6.90, 6.48, 5.88, 5.37, 4.67, 4.26, 2.58, 1.66. ${ }^{13} \mathrm{C} \mathrm{NMR}\left(\mathrm{CD}_{2} \mathrm{Cl}_{2}, 100 \mathrm{MHz}\right), \delta(\mathrm{ppm})$ : $159.95,155.56,151.47,144.57,142.32,141.39,137.61,136.88,136.25,130.37$, $129.96,129.89$, 129.82, 129.53, 127.96, 127.74, 126.01, 119.64, 119.58, 114.49, $114.16,113.82,113.77,113.15,111.79,78.89,75.20,73.28,69.21,55.77,41.75$. 
Structural Characterization Data for P1d/2/3b: Yellow powder; yield: $70.0 \% ; M_{w}$ : 14,800; $M_{w} / M_{n}: 1.5$. IR (film), $v\left(\mathrm{~cm}^{-1}\right): 3061,2934,2855,2174,1665,1603,1580$, 1501, 1485, 1435, 1385, 1296, 1248, 1167, 1142, 1086, 1018, 874, 831, 737, 692, 548. ${ }^{1} \mathrm{H}$ NMR $\left(\mathrm{CD}_{2} \mathrm{Cl}_{2}, 400 \mathrm{MHz}\right), \delta$ (ppm): 8.10, 8.08, 7.81, 7.80, 7.48, 7.46, 7.43, 7.41, $7.33,7.32,7.15,7.13,6.94,6.93,6.90,6.77,6.75,6.36,3.93,3.92,3.78,1.76,1.43$, 1.37. ${ }^{13} \mathrm{C}$ NMR (CD2Cl2, $\left.100 \mathrm{MHz}\right), \delta$ (ppm): 159.25, 158.92, 140.00, 139.83, 136.50, $131.01,129.55,129.28,129.09,128.95,128.72,128.62,128.02,118.55,118.23$, $114.66,113.14,67.50,28.64,28.49,25.30$.

Structural Characterization Data for P1a/2/3c: Yellow gel formed that failed to be dissolved in common organic solvents.

Structural Characterization Data for P1a/2/3ac: Pale yellow powder; yield: 79.1\%; $M_{w}: 8,200 ; M_{w} / M_{n}: 1.8$. IR (film), $v\left(\mathrm{~cm}^{-1}\right): 3057,3022,2176,1578,1485,1443,1402$, 1327, 1298, 1244, 1142, 1086, 1022, 895, 872, 835, 756, 741, 698, 619, 555. ${ }^{1} \mathrm{H}$ NMR (CDCl3, $400 \mathrm{MHz}), \delta$ (ppm): 7.99, 7.96, 7.93, 7.86, 7.48, 7.36, 7.24, 7.01, 6.95, 6.17. ${ }^{13} \mathrm{C} \mathrm{NMR}\left(\mathrm{CDCl}_{3}, 100 \mathrm{MHz}\right), \delta(\mathrm{ppm}): 159.53,158.40,144.85,144.61,142.84,140.98$, $137.73,137.25,136.53,135.81,132.80,132.22,131.33,131.15,130.72,130.15$, $129.71,129.57,129.45,129.14,128.84,128.22,128.04,127.86,127.33,126.78$, 125.40, 118.93 .

Model reaction. Model compound $\mathbf{6}$ was synthesized by selenosulfonation of TPEcontaining alkyne $\mathbf{4}$ with benzenesulfonyl hydrazide 5 and diphenyl diselenide $\mathbf{3 a}$. The procedure was similar with the polymerization process. Pale yellow solid; yield: $91.3 \%$. IR (film), $v\left(\mathrm{~cm}^{-1}\right): 3065,1582,1493,1445,1321,1281,1138,1084,1022,897,853$, 822, 743, 698, 563, 542. ${ }^{1} \mathrm{H}$ NMR (400 MHz, CD2C12), $\delta$ (ppm): 7.53, 7.51, 7.41, 7.39, 7.37, 7.32, 7.30, 7.25, 7.17, 7.15, 7.14, 7.13, 7.12, 7.11, 7.10, 7.08, 7.07, 7.06, 7.03, 7.02, 7.01, 7.00, 6.96, 6.94, 6.91, 6.89, 6.18. ${ }^{13} \mathrm{C} \mathrm{NMR}\left(\mathrm{CD}_{2} \mathrm{Cl}_{2}, 100 \mathrm{MHz}\right), \delta(\mathrm{ppm})$ : $144.44,142.68,142.65,141.53,141.29,139.37,135.91,132.11,131.87,130.76$, $130.71,130.65,130.12,129.48,128.04,127.29,127.26,127.10,127.04,126.86$, 126.15, 125.98, 124.62. HRMS (MALDI-TOF): $m / z$ 654.1121 (M+, calculated 654.1132).

Model compound $\mathbf{8}$ was synthesized by selenosulfonation of phenyl acetylene $\mathbf{4}$ with benzenesulfonyl hydrazide $\mathbf{5}$ and diphenyl diselenide 3a. The procedure was similar with the polymerization process. White solid; yield: $89.6 \%$. ${ }^{1} \mathrm{H}$ NMR $(400 \mathrm{MHz}$, $\left.\mathrm{CDCl}_{3}\right), \delta$ (ppm): 7.60, 7.59, 7.58, 7.48, 7.46, 7.45, 7.44, 7.43, 7.42, 7.41, 7.40, 7.39, 7.38, 7.32, 7.30, 7.28, 7.25, 7.24, 7.23, 7.19, 7.18, 7.17, 7.16, 6.17. ${ }^{13} \mathrm{C} \mathrm{NMR}\left(\mathrm{CDCl}_{3}\right.$, 
$100 \mathrm{MHz}), \delta$ (ppm): 157.93, 141.72, 136.61, 134.52, 132.71, 130.25, 130.20, 129.38, $128.65,128.47,127.93,127.38,126.78,125.62$. HRMS (MALDI-TOF): $\mathrm{m} / \mathrm{z} 400.0037$ (M+, calculated 400.0036).

Oxidation reaction. $24.7 \mathrm{mg}$ of $\mathrm{P} \mathbf{1 a} / \mathbf{2} / \mathbf{3 a}(0.025 \mathrm{mmol})$ was dissolved in $1 \mathrm{~mL}$ of THF and $0.5 \mathrm{~mL}$ of $\mathrm{H}_{2} \mathrm{O}_{2}$ aqueous solution ( $30 \mathrm{wt} \%$ ) was added into the solution slowly. The resulting mixture was stirred in air for $1 \mathrm{~h}$ at room temperature. Then the reaction mixture was diluted with $10 \mathrm{~mL}$ of chloroform and filtered. The filtrate was concentrated and precipitated in pure hexane $(100 \mathrm{~mL})$. Afterwards, the precipitates were collected and dried in vacuum to a constant weight.

Structural Characterization Data for OP1a/2/3a: Yellow powder; yield: $55.6 \% .{ }^{1} \mathrm{H}$ NMR (400 MHz, $\mathrm{CDCl}_{3}$ ), $\delta$ (ppm): 8.08, 8.06, 7.30, 7.28, 7.23, 7.21, 7.12, 7.03, 7.01, 6.95. ${ }^{13} \mathrm{C} \mathrm{NMR}\left(\mathrm{CDCl}_{3}, 100 \mathrm{MHz}\right), \delta$ (ppm): 160.52, 160.42, 160.37, 146.90, 146.84, $143.65,142.49,142.05,141.98,141.54,141.45,140.29$, 137.62, 137.60, 137.54, $137.50,137.48,137.44,132.42,132.38,132.34,132.24,131.74,131.61,131.53$, $131.41,131.17,131.11,130.22$, 129.19, 128.27, 128.14, 128.06, 127.93, 127.88, 127.56, 127.41, 119.68, 119.62, 116.16, 115.92, 93.73, 93.46, 85.88, 85.81, 85.65.

Oxidative model compound 9 was synthesized by a similar procedure. Pale yellow solid; yield: $68.8 \%$. ${ }^{1} \mathrm{H} \mathrm{NMR}\left(400 \mathrm{MHz}, \mathrm{CDCl}_{3}\right), \delta(\mathrm{ppm}): 8.10,8.08,8.07,7.71,7.69$, 7.68, 7.62, 7.60, 7.58, 7.52, 7.50, 7.49, 7.47, 7.45, 7.38, 7.36, 7.34. ${ }^{13} \mathrm{C} \mathrm{NMR}\left(\mathrm{CDCl}_{3}\right.$, $100 \mathrm{MHz}), \delta$ (ppm): 141.75, 134.29, 132.76, 131.68, 129.46, 128.75, 127.41, 117.79, 93.56, 85.34. HRMS (MALDI-TOF): $\mathrm{m} / z$ 243.0497 (M+, calculated 242.0402).

Oxidative model compound $\mathbf{1 0}$ was synthesized by a similar procedure. Yellow solid; yield: 69.5\%. ${ }^{1} \mathrm{H}$ NMR (400 MHz, $\mathrm{CDCl}_{3}$ ), $\delta$ (ppm): 8.06, 8.05, 8.04, 7.69, 7.68, 7.67, 7.66, 7.65, 7.60, 7.58, 7.57, 7.25, 7.24, 7.13, 7.12, 7.11, 7.10, 7.09, 7.08, 7.03, 7.01, 7.00, 6.99, 6.97, 6.96, 6.95. ${ }^{13} \mathrm{C} \mathrm{NMR}\left(\mathrm{CDCl}_{3}, 100 \mathrm{MHz}\right), \delta(\mathrm{ppm}): 147.68,143.00$, $142.96,142.93,142.77,141.87,139.51,134.11,132.16,131.64,131.28,131.26$, 131.20, 129.37, 127.96, 127.94, 127.74, 127.40, 127.06, 126.89, 115.40, 94.02, 85.38. HRMS (MALDI-TOF): $m / z$ 496.1514 (M+, calculated 496.1497).

\section{Optimization of Polymerization Conditions}

First, the solvent effect on the polymerization was investigated (Table S1). Although acetonitrile was suggested as the best solvent for the model reaction, polymers with poor solubility were obtained using this solvent for the polymerization. Therefore, we 
tried other pure solvents. THF and DCE gave trace amount of products while DMF and DMSO produced only oligomers (Table S1, entry 1-4). Afterwards, solvent mixtures were applied to solve the solubility problem (Table S1, entry 5-7). When the polymerization was carried out in $\mathrm{DMF} / \mathrm{MeCN}$ mixture, a partially soluble polymer was formed $\left(M_{w}=12,600\right.$, yield $\left.=92.3 \%\right)$. Then we shortened the polymerization time from $24 \mathrm{~h}$ to $2 \mathrm{~h}$ (Table S1, entry 8). The above results suggested that MeCN played an essential role in the polymerization and $\mathrm{DMF} / \mathrm{MeCN}$ mixtures was the most suitable solvents.

Table S1. Effect of Solvent on the Polymerization of 1a, 2 and $3 a^{a}$

\begin{tabular}{llccc}
\hline entry & \multicolumn{1}{c}{ solvent } & yield (\%) & $M_{w}{ }^{b}$ & $M_{w} / M_{n}{ }^{b}$ \\
\hline $1^{c}$ & DMF & 64.1 & 2,900 & 1.2 \\
2 & DMSO & 63.3 & 2,400 & 1.2 \\
3 & DCE & trace & - & - \\
4 & THF & trace & - & - \\
5 & THF/MeCN & 46.0 & 4,500 & 1.3 \\
6 & DMSO/MeCN & 79.7 & 4,800 & 1.2 \\
7 & DMF/MeCN & 92.3 & gel $^{c}$ & - \\
$8^{d}$ & DMF/MeCN & 81.8 & 8,200 & 1.4
\end{tabular}

${ }^{a}$ Carried out in different solvents under nitrogen for $24 \mathrm{~h}$ at room temperature in the presence of $\mathrm{Cu}(\mathrm{MeCN})_{4} \mathrm{PF}_{6}$ and $\mathrm{K}_{2} \mathrm{~S}_{2} \mathrm{O}_{8}$. If mixed solvents were used, the volume ratio was $1: 1 .[\mathbf{1 a}]=[\mathbf{2}]=[\mathbf{3 a}]=0.2 \mathrm{M},\left[\mathrm{Cu}(\mathrm{MeCN})_{4} \mathrm{PF}_{6}\right]=0.02 \mathrm{M},\left[\mathrm{K}_{2} \mathrm{~S}_{2} \mathrm{O}_{8}\right]=0.8 \mathrm{M}$. ${ }^{b}$ Determined by GPC in THF on the basis of a linear polystyrene calibration. Abbreviation: $\mathrm{DMF}=N, N$-dimethylformamide, $\mathrm{DMSO}=$ dimethyl sulfoxide, $\mathrm{THF}=$ tetrahydrofuran, $\mathrm{DCE}=$ dichloroethane and $\mathrm{MeCN}=$ acetonitrile. ${ }^{c} \mathrm{GPC}$ data for soluble part: $M_{w}=12,600, M_{w} / M_{n}=1.4 .{ }^{d}$ Carried out under same conditions for $2 \mathrm{~h}$.

Therefore, a mixture of acetonitrile and DMF were used to solve the solubility problem. As shown in Table S2, the solvent ratio effect on the polymerization was also studied. The results showed that an equal amount of two solvents produced the highest molecular weight and yield (Table S2, entry 2). Increasing the amount of DMF or acetonitrile resulted in the formation of oligomers in poor yields (Table S2, entry 1 and entry 3-5). 
Table S2. Solvent Ratio Effect on the Polymerization ${ }^{a}$

\begin{tabular}{lcccc}
\hline entry & $\mathrm{DMF} / \mathrm{MeCN}(\mathrm{v} / \mathrm{v})$ & yield (\%) & $M_{w}{ }^{b}$ & $M_{w} / M_{n}{ }^{b}$ \\
\hline 1 & $1: 4$ & 10.2 & 2,900 & 1.1 \\
$2^{c}$ & $1: 1$ & 81.8 & 8,200 & 1.4 \\
3 & $4: 1$ & 52.7 & 4,600 & 1.2 \\
4 & $9: 1$ & 55.4 & 3,300 & 1.1 \\
5 & $19: 1$ & 57.8 & 2,900 & 1.1
\end{tabular}

${ }^{a}$ Carried out in $\mathrm{DMF} / \mathrm{MeCN}$ mixture with different volume ratios under nitrogen for 2 $\mathrm{h}$ at room temperature in the presence of $\mathrm{Cu}(\mathrm{MeCN})_{4} \mathrm{PF}_{6}$ and $\mathrm{K}_{2} \mathrm{~S}_{2} \mathrm{O}_{8}$. [1a] $=[\mathbf{2}]=[\mathbf{3 a}]$ $=0.2 \mathrm{M},\left[\mathrm{Cu}(\mathrm{MeCN})_{4} \mathrm{PF}_{6}\right]=0.02 \mathrm{M},\left[\mathrm{K}_{2} \mathrm{~S}_{2} \mathrm{O}_{8}\right]=0.8 \mathrm{M} .{ }^{b}$ Determined by GPC in THF on the basis of a linear polystyrene calibration. ${ }^{c}$ Data taken from Table S1, entry 8.

Next, we evaluated the effect of different catalysts on the polymerization using $\mathrm{DMF} / \mathrm{MeCN}$ mixture $(\mathrm{v} / \mathrm{v}=1: 1)$ as solvent. $\mathrm{Cu}(\mathrm{MeCN})_{4} \mathrm{PF}_{6}$ was suggested by the small molecule reaction and other four common copper catalysts were also tested with this polymerization. Among the tested catalysts, $\mathrm{Cu}(\mathrm{MeCN})_{4} \mathrm{PF}_{6}$ gave the best performance, affording a polymer with the highest $M_{w}$ in a good yield (Table S3, entry 1). Trace amount of product was obtained when $\mathrm{CuBr}$ and $\mathrm{Cu}(\mathrm{OAc})_{2} \cdot \mathrm{H}_{2} \mathrm{O}$ were used as catalysts (Table S3, entry 3 and 5). $\mathrm{CuCl}$ also gave a satisfactory yield but the corresponding weight-average molecular weight of the obtained polymer was low (Table S3, entry 4).

Table S3. Effect of Catalyst on the Polymerization of 1a, 2 and $3 a^{a}$

\begin{tabular}{llccc}
\hline entry & \multicolumn{1}{c}{ catalyst } & yield (\%) & $M_{w}{ }^{b}$ & $M_{w} / M_{n}{ }^{b}$ \\
\hline $1^{c}$ & $\mathrm{Cu}(\mathrm{MeCN})_{4} \mathrm{PF}_{6}$ & 81.8 & 8,200 & 1.4 \\
2 & $\mathrm{CuI}$ & 21.1 & 1,400 & 1.3 \\
3 & $\mathrm{CuBr}$ & trace & - & - \\
4 & $\mathrm{CuCl}$ & 85.5 & 5,200 & 1.2 \\
5 & $\mathrm{Cu}(\mathrm{OAc})_{2} \cdot \mathrm{H}_{2} \mathrm{O}$ & trace & - & -
\end{tabular}

${ }^{a}$ Carried out in DMF/MeCN mixture $(\mathrm{v} / \mathrm{v}=1: 1)$ under nitrogen for $2 \mathrm{~h}$ at room temperature in the presence of different catalyst and $\mathrm{K}_{2} \mathrm{~S}_{2} \mathrm{O}_{8} \cdot[\mathbf{1 a}]=[\mathbf{2}]=[\mathbf{3 a}]=0.2 \mathrm{M}$, [catalyst $]=0.02 \mathrm{M},\left[\mathrm{K}_{2} \mathrm{~S}_{2} \mathrm{O}_{8}\right]=0.8 \mathrm{M} .{ }^{b}$ Determined by GPC in THF on the basis of a linear polystyrene calibration. ${ }^{c}$ Data taken from Table S1, entry 8. 
The influence of monomer concentration on the polymerization was also studied. When we increased the monomer concentration from $0.1 \mathrm{M}$ to $0.2 \mathrm{M}$, both $M_{w}$ and yields increased (Table S4, entry 1-2). However, further increasing the concentration led to formation of oligomers (Table S4, entry 3-4). The best polymerization result was achieved at a monomer concentration of $0.2 \mathrm{M}$.

Table S4. Effect of Concentration on the Polymerization of 1a, 2 and $3 a^{a}$

\begin{tabular}{lcccc}
\hline entry & {$[\mathbf{1 a}](\mathrm{M})$} & yield (\%) & $M_{w}{ }^{b}$ & $M_{w} / M_{n}{ }^{b}$ \\
\hline 1 & 0.10 & 71.8 & 4,200 & 1.2 \\
$2^{c}$ & 0.20 & 81.8 & 8,200 & 1.4 \\
3 & 0.25 & 80.7 & 2,000 & 1.2 \\
4 & 0.30 & 17.2 & 1,400 & 1.1
\end{tabular}

${ }^{a}$ Carried out in $\mathrm{DMF} / \mathrm{MeCN}$ mixture $(\mathrm{v} / \mathrm{v}=1: 1)$ under nitrogen for $2 \mathrm{~h}$ at room temperature in the presence of $\mathrm{Cu}(\mathrm{MeCN})_{4} \mathrm{PF}_{6}$ and $\mathrm{K}_{2} \mathrm{~S}_{2} \mathrm{O}_{8} .[\mathbf{1 a}]=[\mathbf{2}]=[\mathbf{3 a}]$, $\left[\mathrm{Cu}(\mathrm{MeCN})_{4} \mathrm{PF}_{6}\right]=10 \mathrm{~mol} \%,\left[\mathrm{~K}_{2} \mathrm{~S}_{2} \mathrm{O}_{8}\right]=4$ equiv to that of 1a. ${ }^{b}$ Determined by GPC in THF on the basis of a linear polystyrene calibration. ${ }^{c}$ Data taken from Table S1, entry 8.

Afterwards, we followed the time course on the polymerization using the above optimized conditions (Table S5). The yields increased dramatically from $1.5 \mathrm{~h}$ to $2 \mathrm{~h}$, then kept almost unchanged from $2 \mathrm{~h}$ to $3 \mathrm{~h}$. The molecular weight of the polymers increased linearly with the prolonged reaction time. Therefore, we chose $3 \mathrm{~h}$ as the best condition.

Table S5. Time course on the Polymerization ${ }^{a}$

\begin{tabular}{lllll}
\hline entry & time (h) & yield (\%) & $M_{w}{ }^{b}$ & $M_{w} / M_{n}{ }^{b}$ \\
\hline 1 & 1.5 & 62.4 & 7,100 & 1.4 \\
$2^{c}$ & 2.0 & 81.8 & 8,200 & 1.4 \\
3 & 2.5 & 90.3 & 9,800 & 1.5 \\
4 & 3.0 & 92.3 & 12,600 & 1.8
\end{tabular}

${ }^{a}$ Carried out in $\mathrm{DMF} / \mathrm{MeCN}$ mixture $(\mathrm{v} / \mathrm{v}=1: 1)$ under nitrogen at room temperature in the presence of $\mathrm{Cu}(\mathrm{MeCN})_{4} \mathrm{PF}_{6}$ and $\mathrm{K}_{2} \mathrm{~S}_{2} \mathrm{O}_{8} \cdot[\mathbf{1 a}]=[\mathbf{2}]=[\mathbf{3 a}]=0.2 \mathrm{M},\left[\mathrm{Cu}(\mathrm{MeCN})_{4} \mathrm{PF}_{6}\right]$ $=0.02 \mathrm{M},\left[\mathrm{K}_{2} \mathrm{~S}_{2} \mathrm{O}_{8}\right]=0.8 \mathrm{M} .{ }^{b}$ Determined by GPC in THF on the basis of a linear polystyrene calibration. ${ }^{c}$ Data taken from Table S1, entry 8. 


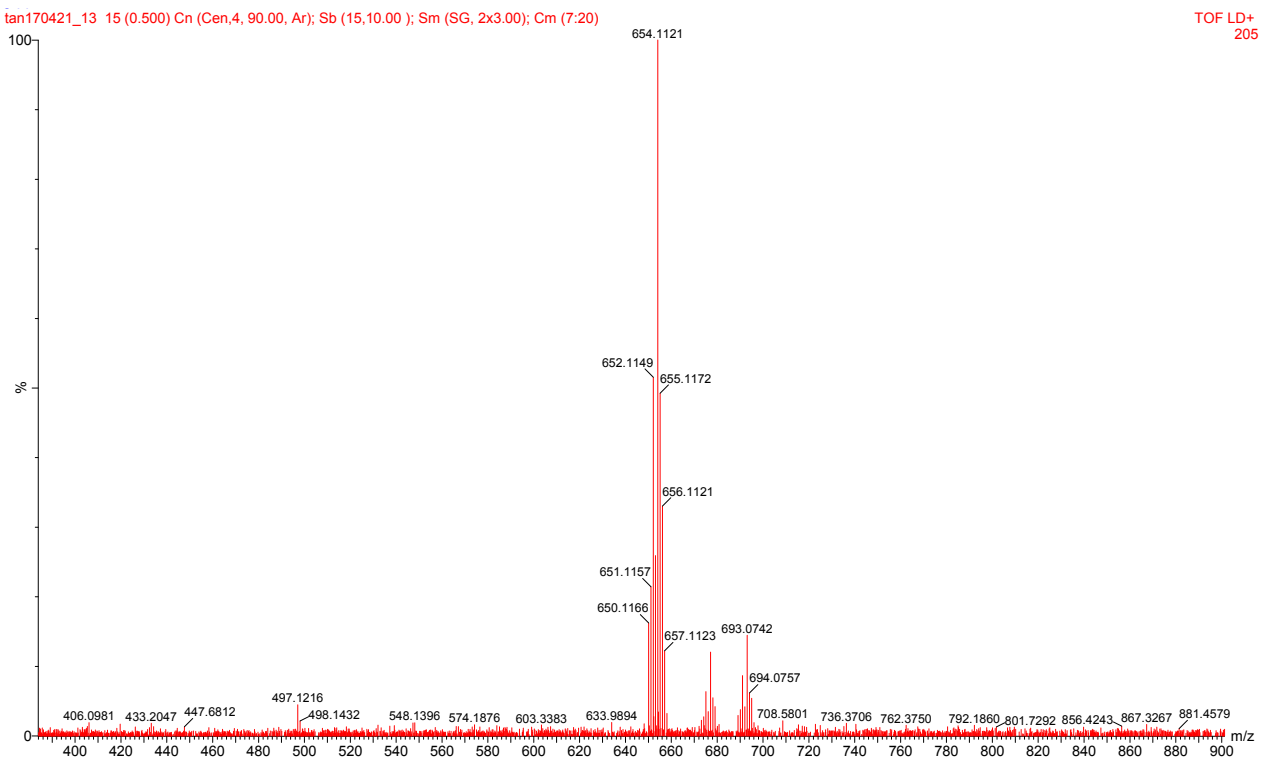

Figure S1. High-resolution mass spectra of model compound 6.

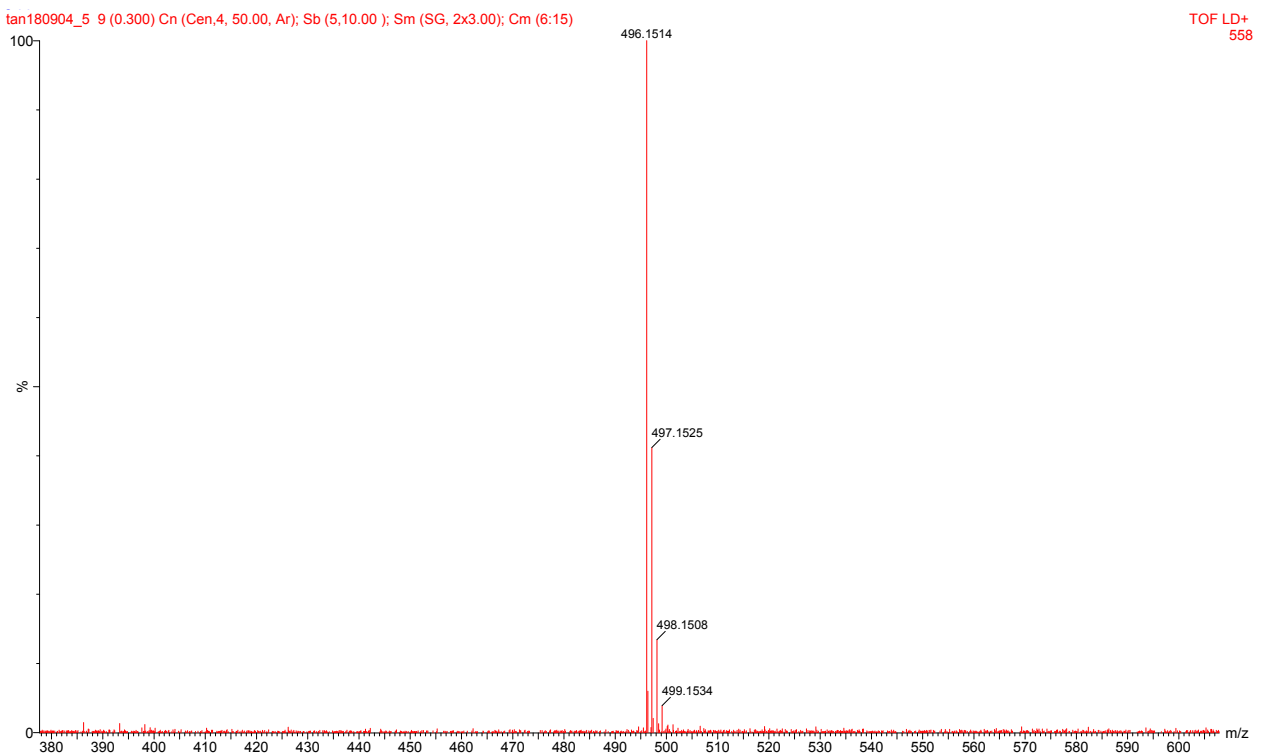

Figure S2. High-resolution mass spectra of model compound 10. 


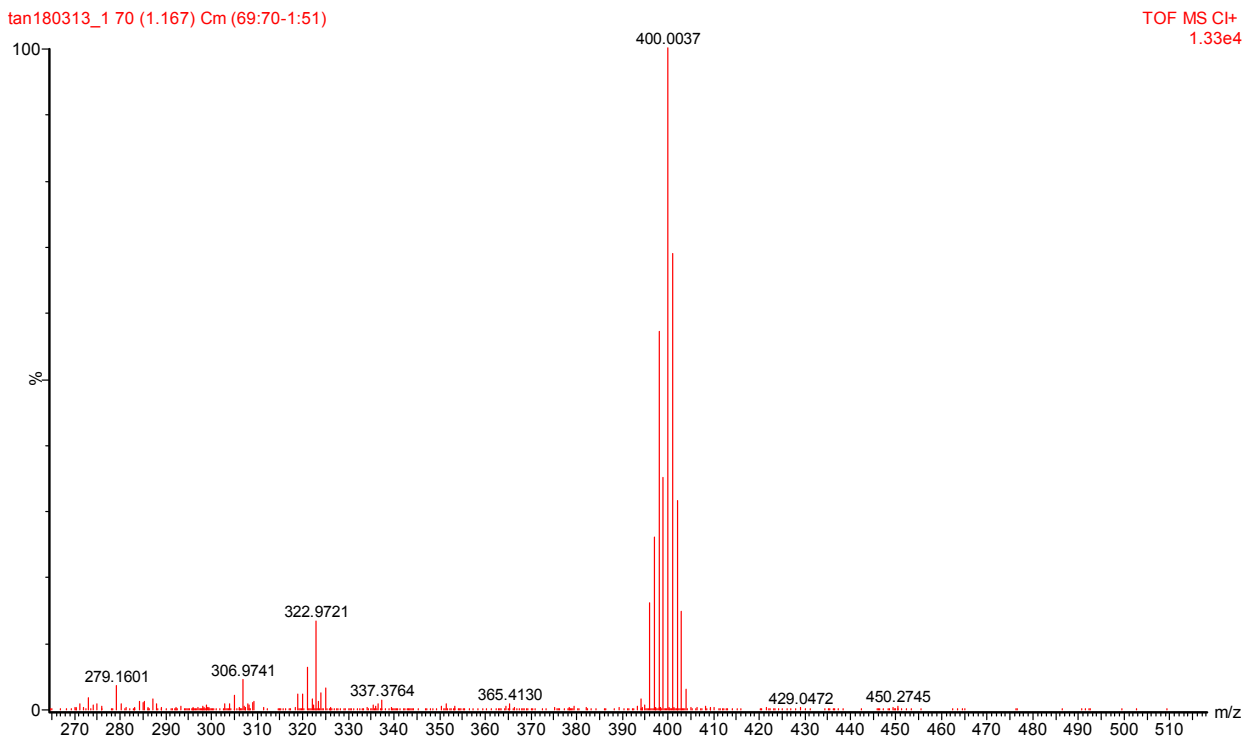

Figure S3. High-resolution mass spectra of model compound $\mathbf{8}$.

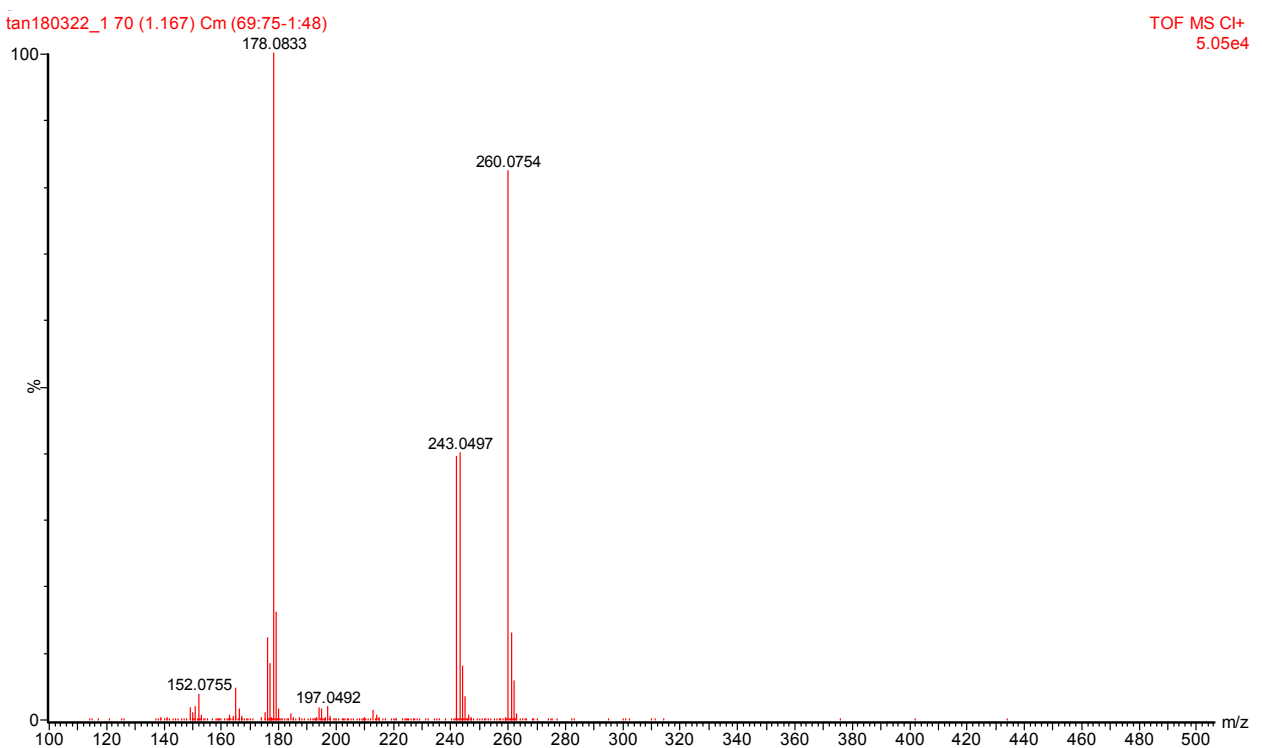

Figure S4. High-resolution mass spectra of oxidative model compound 9. 
Table S6. Summary of Crystal Data of 8.

Complex

Empirical formula

Formula weight

Temperature/K

Crystal system

Space group

$\mathrm{a} / \AA$

$\mathrm{b} / \AA$

$\mathrm{c} / \AA$

$\alpha /^{\circ}$

$\beta /{ }^{\circ}$

$\gamma /{ }^{\circ}$

Volume $/ \AA^{3}$

Z

$\rho_{\text {calc }} \mathrm{g} / \mathrm{cm}^{3}$

$\mu / \mathrm{mm}^{-1}$

$\mathrm{F}(000)$

Crystal size $/ \mathrm{mm}^{3}$

Radiation

$2 \Theta$ range for data collection $/{ }^{\circ}$

Index ranges

Reflections collected

Independent reflections

Data/restraints/parameters

Completeness to theta $=66.5^{\circ}$

Goodness-of-fit on $\mathrm{F}^{2}$

Final $\mathrm{R}$ indexes $[\mathrm{I}>=2 \sigma(\mathrm{I})]$

Final $\mathrm{R}$ indexes [all data]

Largest diff. peak/hole/e $\AA^{-3}$

\section{8}

$\mathrm{C}_{20} \mathrm{H}_{16} \mathrm{O}_{2} \mathrm{SSe}$

399.35

100.01(10)

monoclinic

$\mathrm{P} 2{ }_{1} / \mathrm{c}$

$15.9736(3)$

5.31980(10)

20.0252(4)

90

$96.278(2)$

90

1691.46(6)

4

1.568

4.230

808.0

$$
0.05 \times 0.05 \times 0.04
$$

$\mathrm{CuK} \alpha(\lambda=1.54184)$

8.886 to 134.832

$-12 \leq \mathrm{h} \leq 19,-6 \leq \mathrm{k} \leq 4,-22 \leq 1 \leq 23$

4902

$2989\left[\mathrm{R}_{\text {int }}=0.0158, \mathrm{R}_{\text {sigma }}=0.0253\right]$

2989/144/307

$98.3 \%$

1.029

$\mathrm{R}_{1}=0.0259, \mathrm{wR}_{2}=0.0593$

$\mathrm{R}_{1}=0.0303, \mathrm{wR}_{2}=0.0613$

$0.62 /-0.59$ 
Table S7. Summary of Crystal Data of 9.

Complex

Empirical formula

Formula weight

Temperature/K

Crystal system

Space group

$\mathrm{a} / \AA$

$\mathrm{b} / \AA$

$\mathrm{c} / \AA$

$\alpha /{ }^{\circ}$

$\beta /{ }^{\circ}$

$\gamma /{ }^{\circ}$

Volume $/ \AA^{3}$

Z

$\rho_{\text {calc }} \mathrm{g} / \mathrm{cm}^{3}$

$\mu / \mathrm{mm}^{-1}$

$\mathrm{F}(000)$

Crystal size $/ \mathrm{mm}^{3}$

Radiation

$2 \Theta$ range for data collection/ ${ }^{\circ}$

Index ranges

Reflections collected

Independent reflections

Data/restraints/parameters

Completeness to theta $=66.5^{\circ}$

Goodness-of-fit on $\mathrm{F}^{2}$

Final R indexes $[\mathrm{I}>=2 \sigma(\mathrm{I})]$

Final $\mathrm{R}$ indexes [all data]

Largest diff. peak/hole/e $\AA^{-3}$

\section{9}

$\mathrm{C}_{14} \mathrm{H}_{10} \mathrm{O}_{2} \mathrm{~S}$

242.28

$100.00(10)$

orthorhombic

Pbca

$11.1215(2)$

14.9694(2)

28.8591(4)

90

90

90

4804.53(13)

16

1.340

2.279

2016.0

$$
0.25 \times 0.22 \times 0.2
$$

$\operatorname{CuK} \alpha(\lambda=1.54184)$

10.042 to 134.992

$-13 \leq \mathrm{h} \leq 12,-17 \leq \mathrm{k} \leq 13,-25 \leq 1 \leq 34$

25964

$4307\left[\mathrm{R}_{\text {int }}=0.0291, \mathrm{R}_{\text {sigma }}=0.0169\right]$

$4307 / 0 / 307$

$99.7 \%$

1.011

$\mathrm{R} 1=0.0293, \mathrm{wR}_{2}=0.0795$

$\mathrm{R} 1=0.0330, \mathrm{wR}_{2}=0.0820$

$0.41 /-0.34$ 

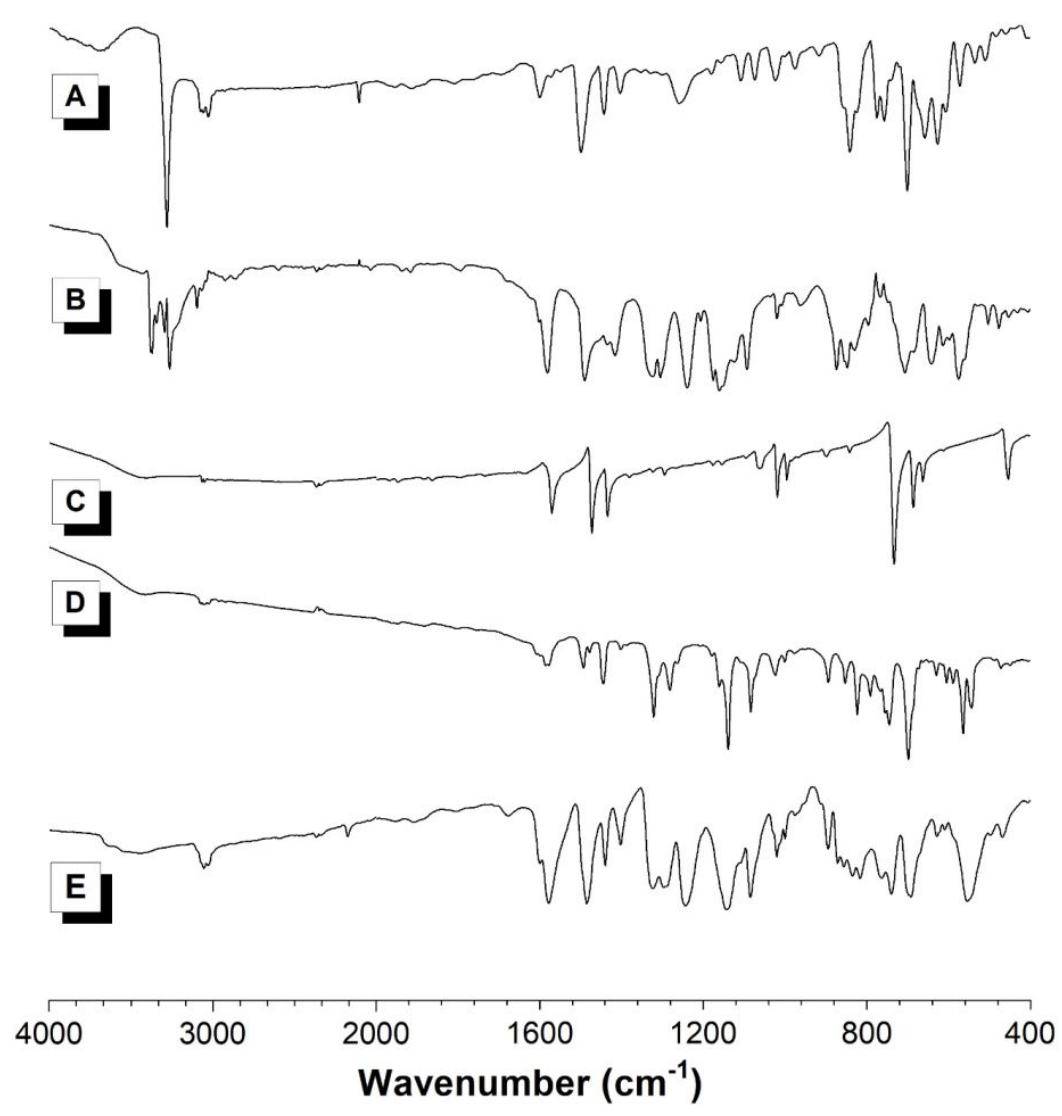

Figure S5. IR spectra of (A) 1a, (B) 2, (C) 3a, (D) 6 and (E) P1a/2/3a.

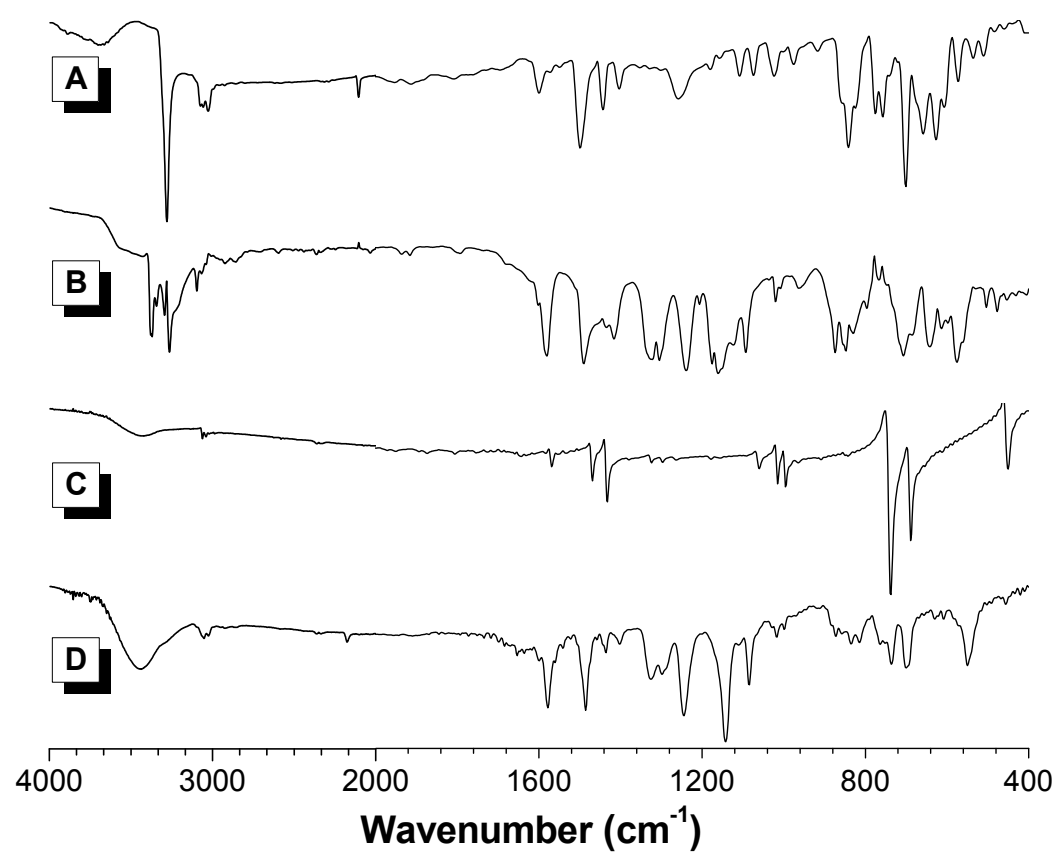

Figure S6. IR spectra of (A) 1a, (B) 2, (C) 3b and (D) P1a/2/3b. 


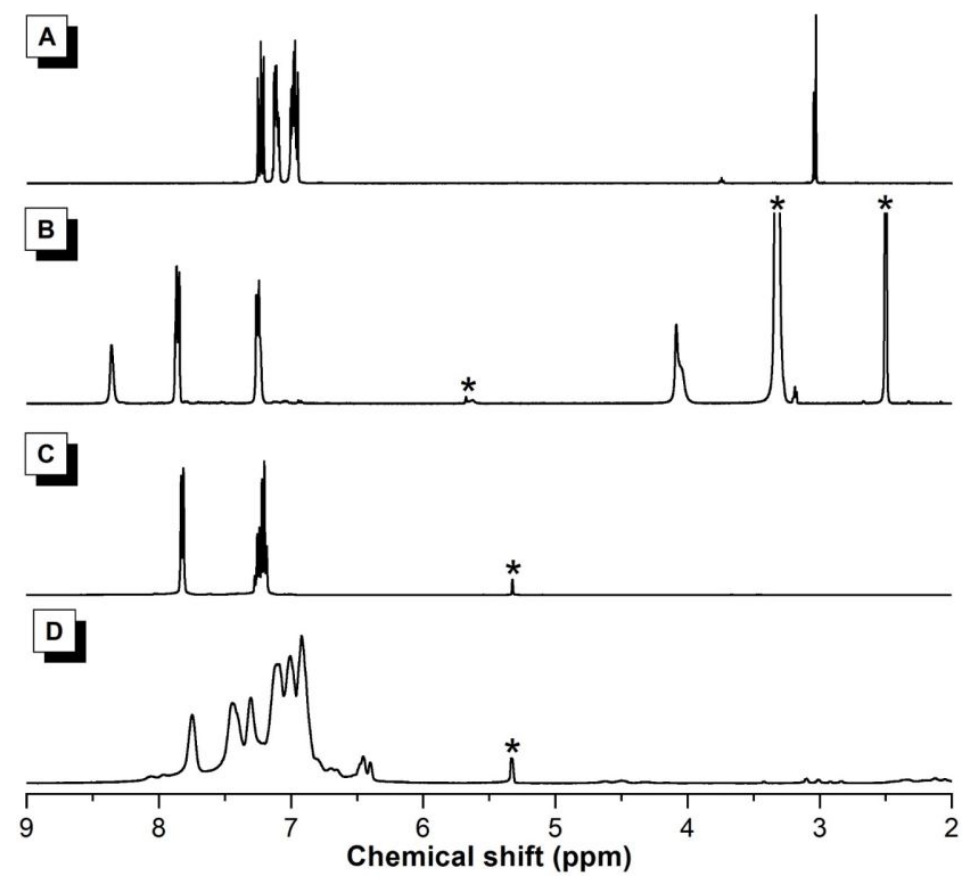

Figure S7. ${ }^{1} \mathrm{H}$ NMR spectra of (A) 1 a in chloroform- $d$, (B) 2 in dimethyl sulfoxide- $d_{6}$, (C) $\mathbf{3 b}$ and (D) P1a/2/3b in dichloromethane- $d_{2}$. The solvent peaks were marked with asterisks

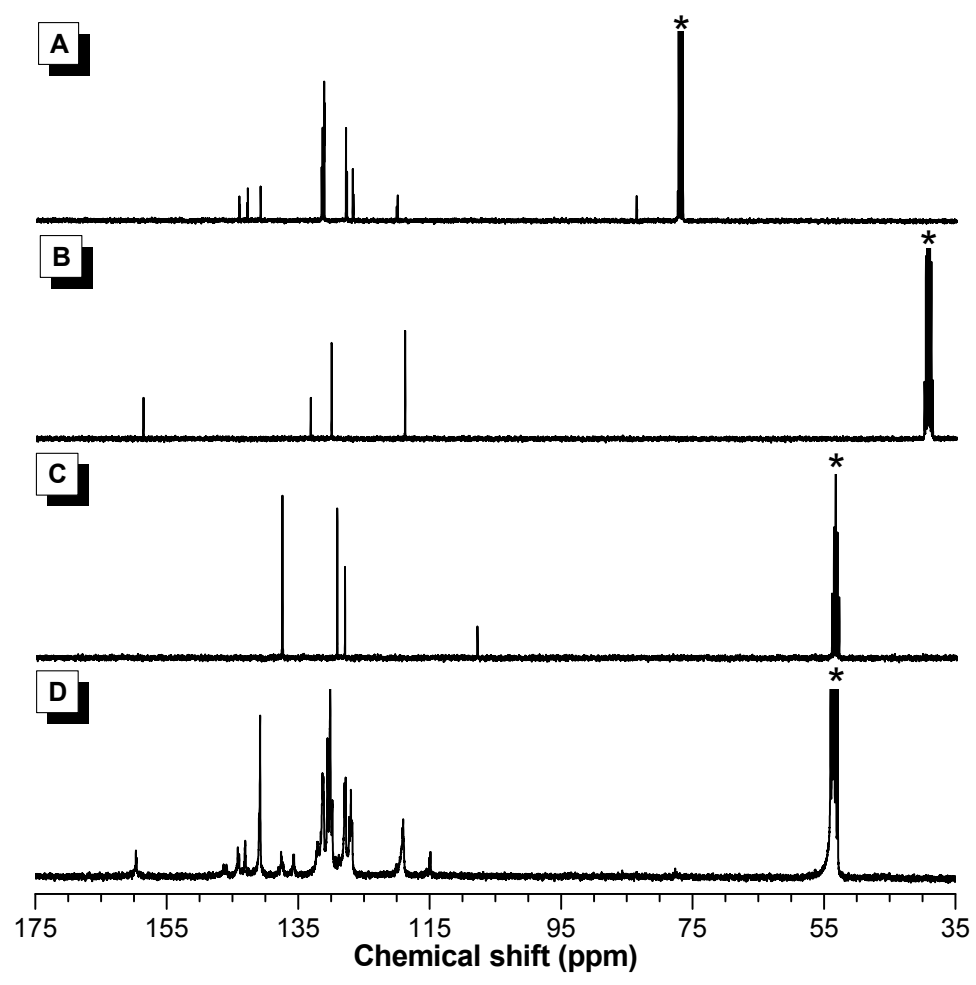

Figure S8. ${ }^{13} \mathrm{C}$ NMR spectra of (A) $\mathbf{1 a}$ in chloroform- $d$, (B) 2 in dimethyl sulfoxide$d_{6},(\mathrm{C}) \mathbf{3 b}$ and (D) P1a/2/3b in dichloromethane- $d_{2}$. The solvent peaks were marked with asterisks. 

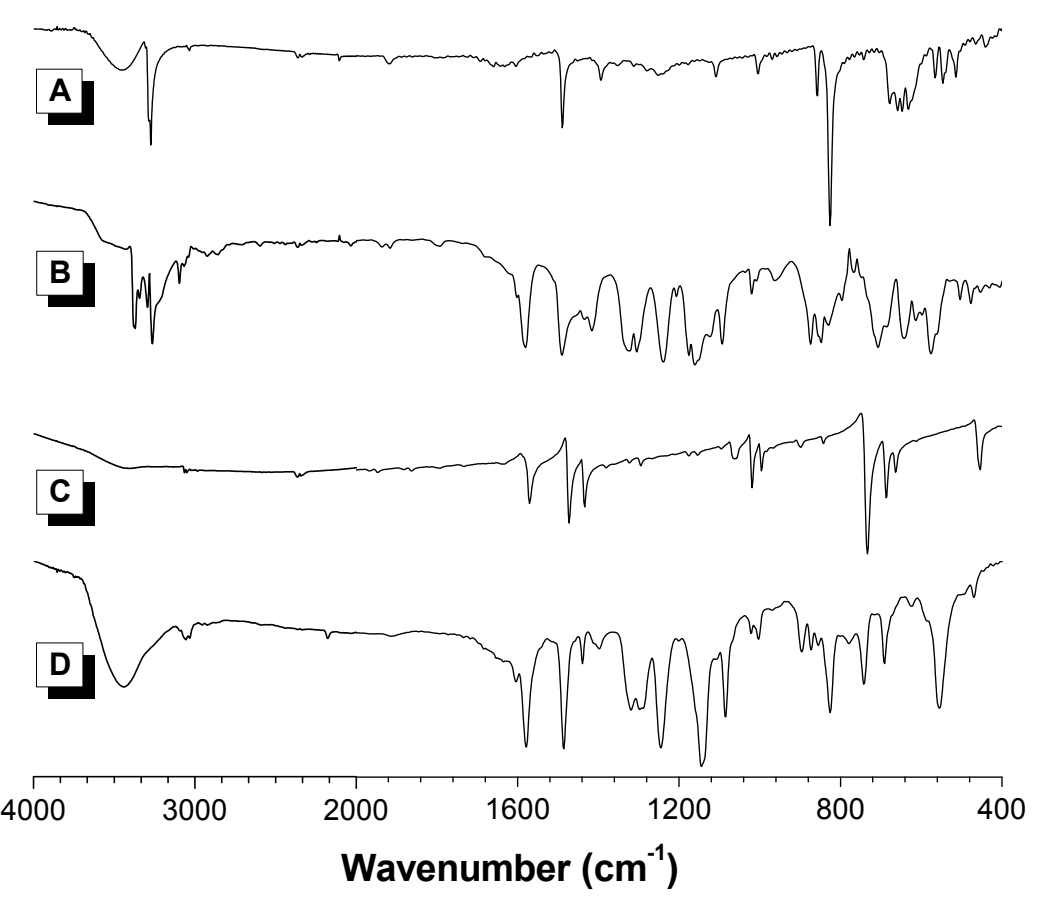

Figure S9. IR spectra of (A) 1b, (B) 2, (C) 3a and (D) P1b/2/3a.

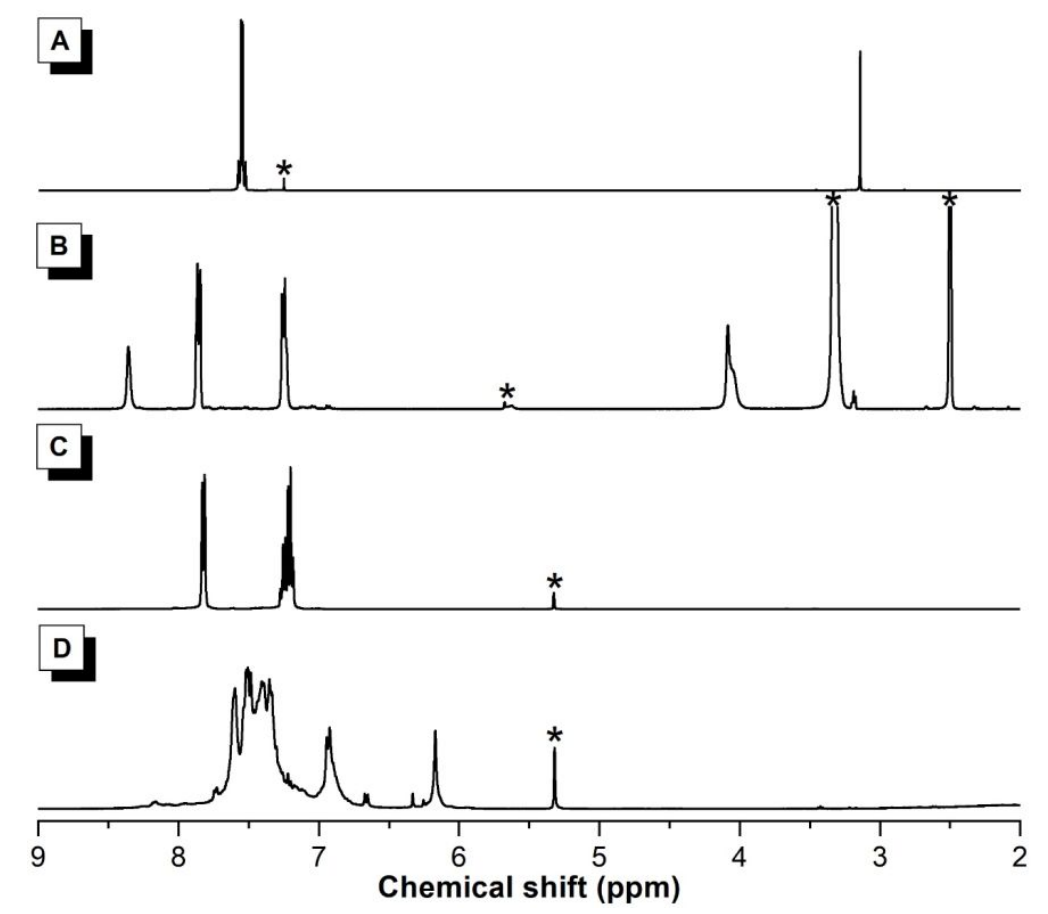

Figure S10. ${ }^{1} \mathrm{H}$ NMR spectra of (A) $1 \mathrm{~b}$ in chloroform- $d$, (B) 2 in dimethyl sulfoxide$d_{6},(\mathrm{C}) \mathbf{3 a}$ and (D) P1b/2/3a in dichloromethane- $d_{2}$. The solvent peaks were marked with asterisks. 


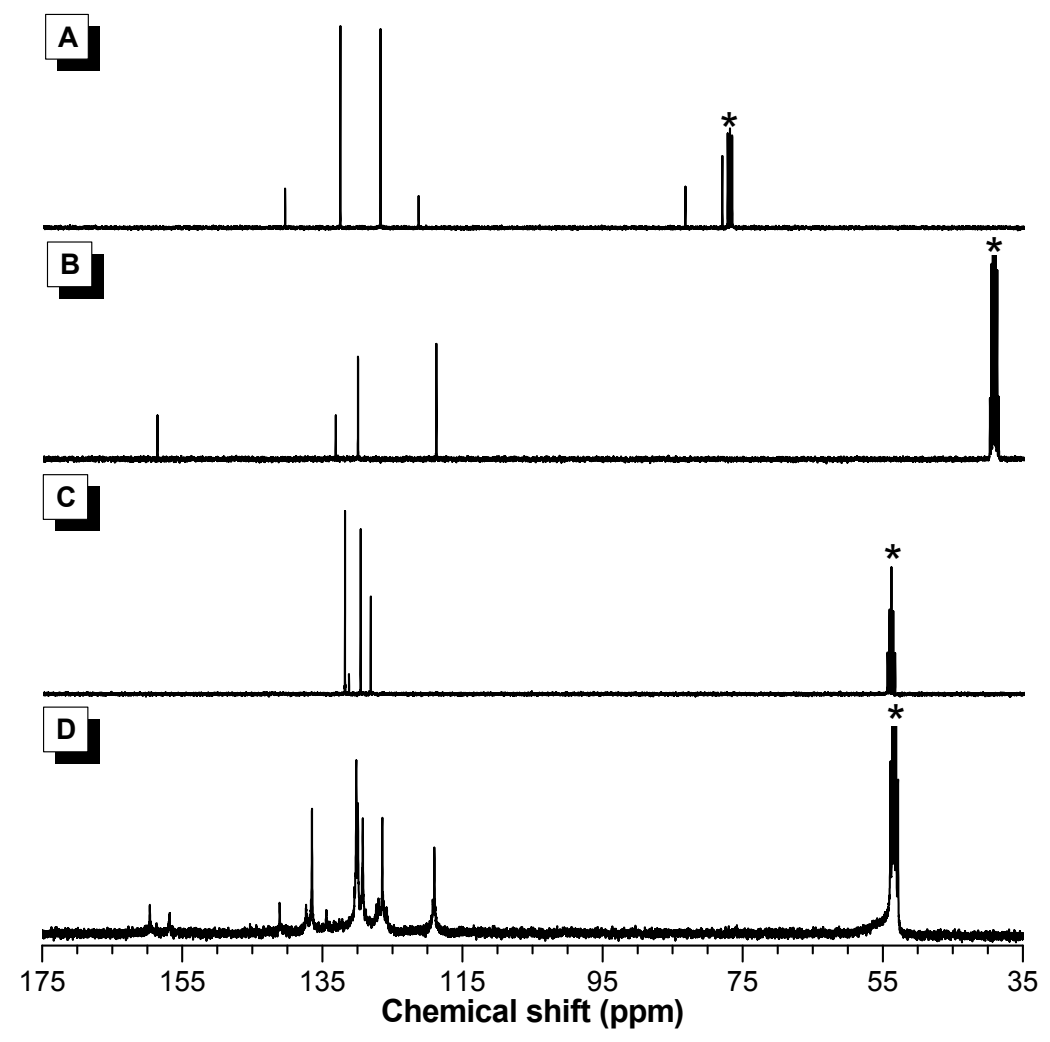

Figure S11. ${ }^{13} \mathrm{C}$ NMR spectra of (A) $\mathbf{1 b}$ in chloroform- $d$, (B) 2 in dimethyl sulfoxide$d_{6},(\mathrm{C}) \mathbf{3 a}$ and (D) P1b/2/3a in dichloromethane- $d_{2}$. The solvent peaks were marked with asterisks.

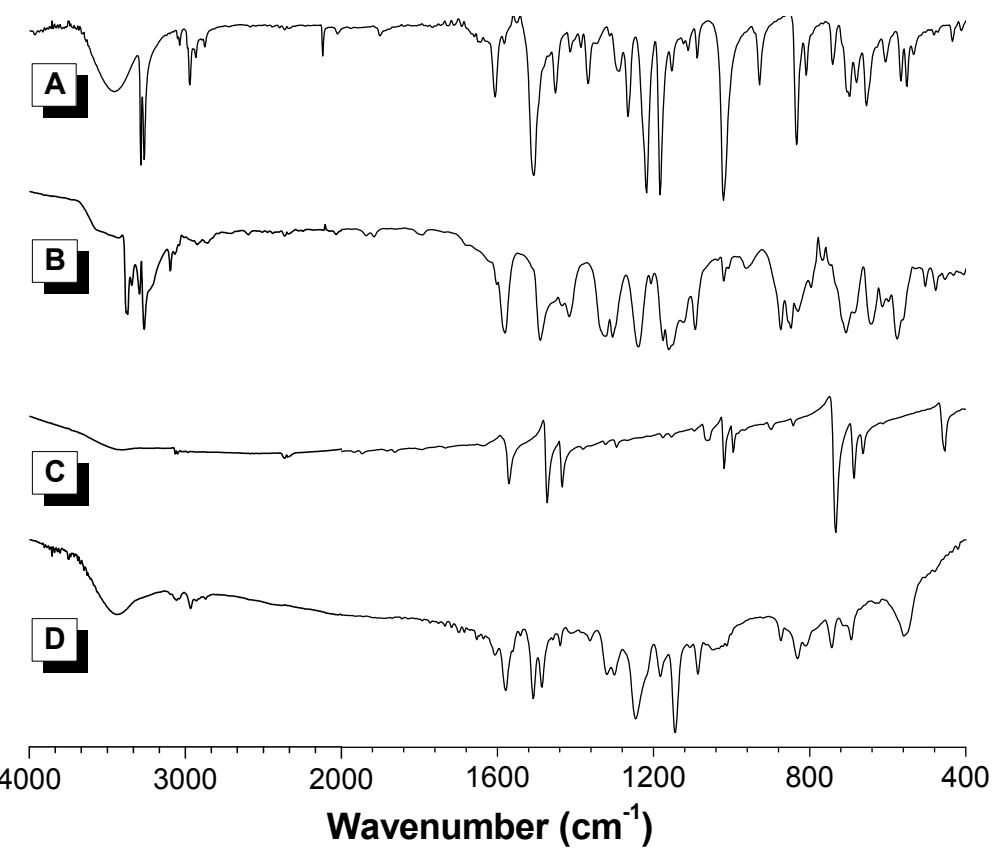

Figure S12. IR spectra of (A) 1c, (B) 2, (C) 3a and (D) P1c/2/3a. 


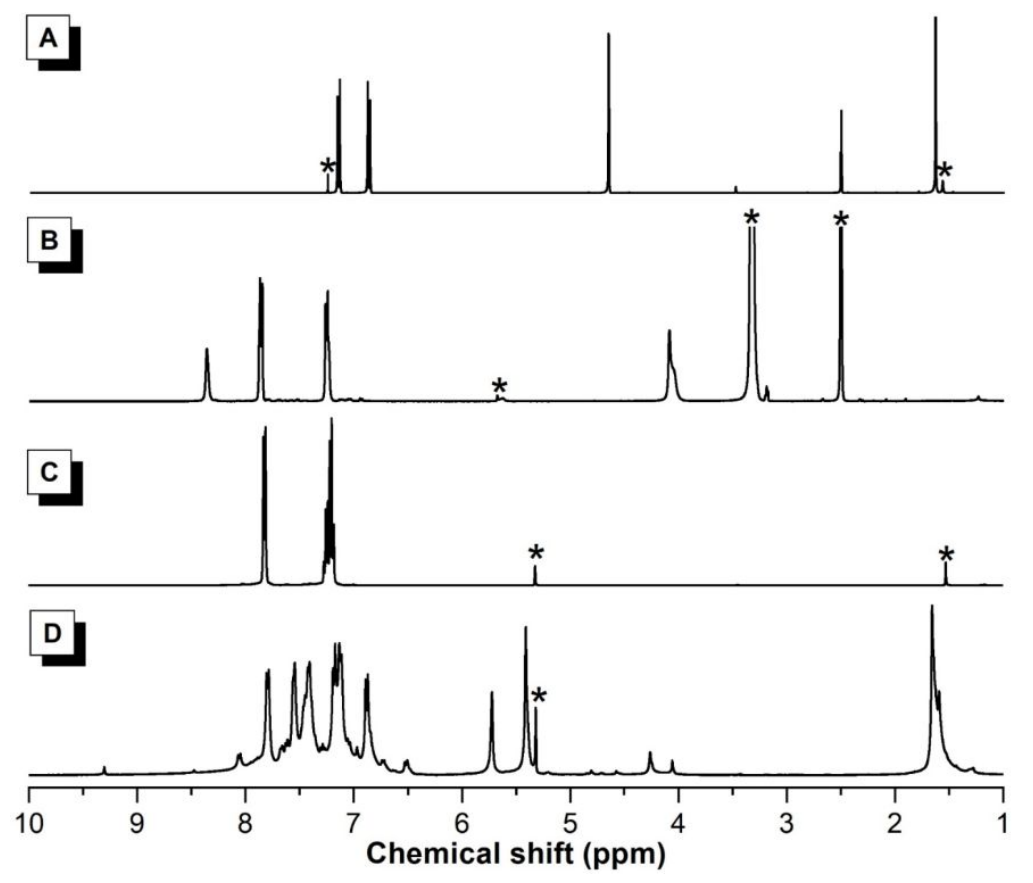

Figure S13. ${ }^{1} \mathrm{H}$ NMR spectra of (A) $1 \mathrm{c}$ in chloroform- $d$, (B) 2 in dimethyl sulfoxide$d_{6},(\mathrm{C}) \mathbf{3 a}$ and (D) P1c/2/3a in dichloromethane- $d_{2}$. The solvent peaks were marked with asterisks.

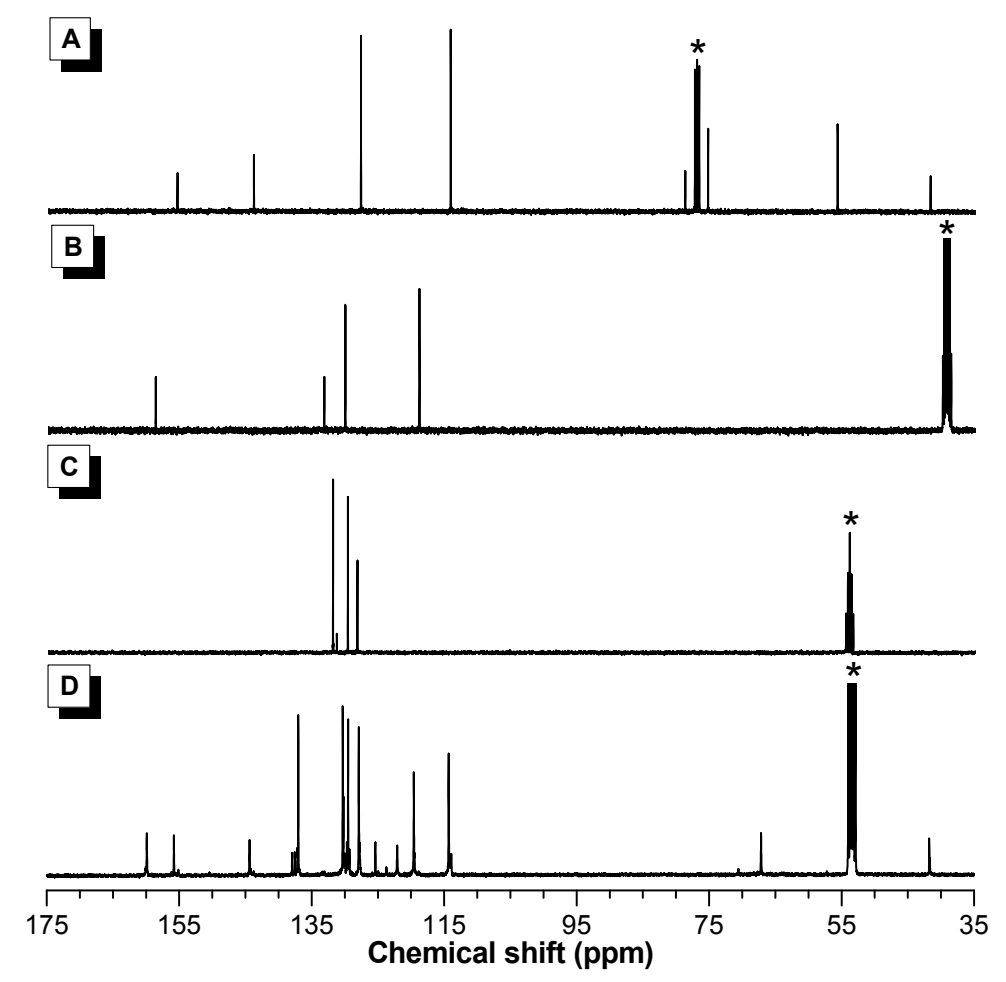

Figure S14. ${ }^{13} \mathrm{C}$ NMR spectra of (A) $1 \mathrm{c}$ in chloroform- $d$, (B) 2 in dimethyl sulfoxide$d_{6},(\mathrm{C}) 3 \mathbf{a}$ and (D) P1c/2/3a in dichloromethane- $d_{2}$. The solvent peaks were marked with asterisks. 


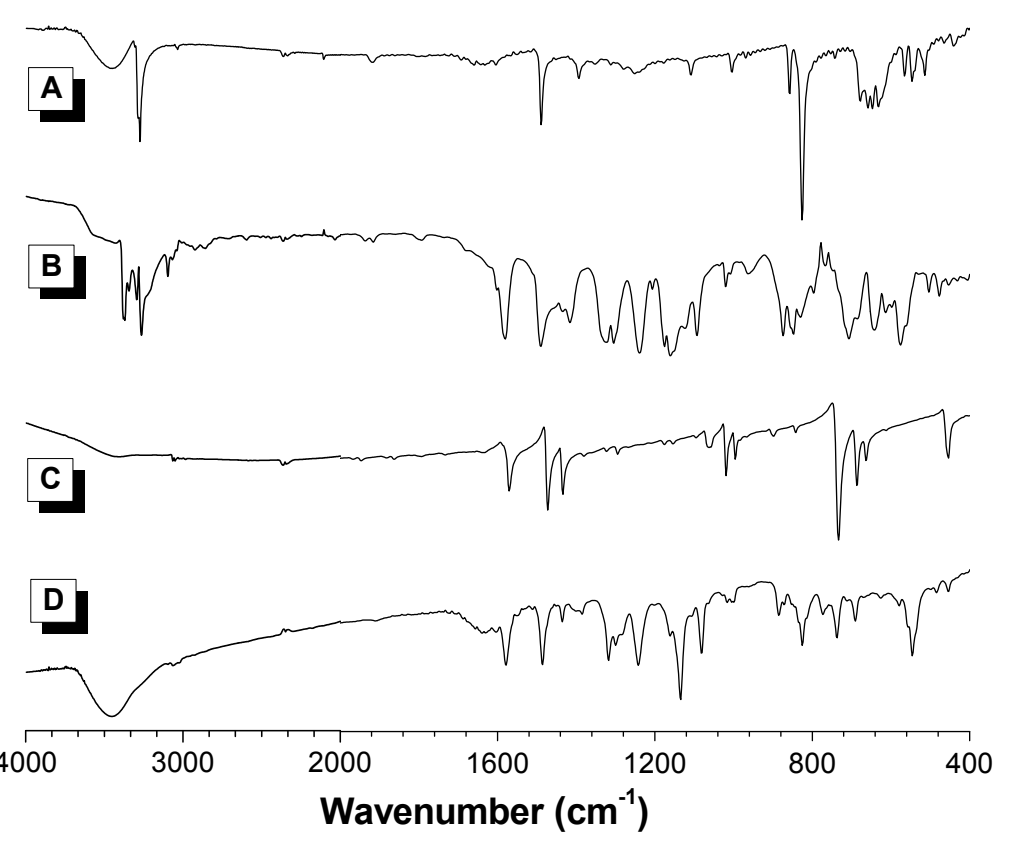

Figure S15. IR spectra of (A) 1b, (B) 2, (C) 3b and (D) P1b/2/3b.

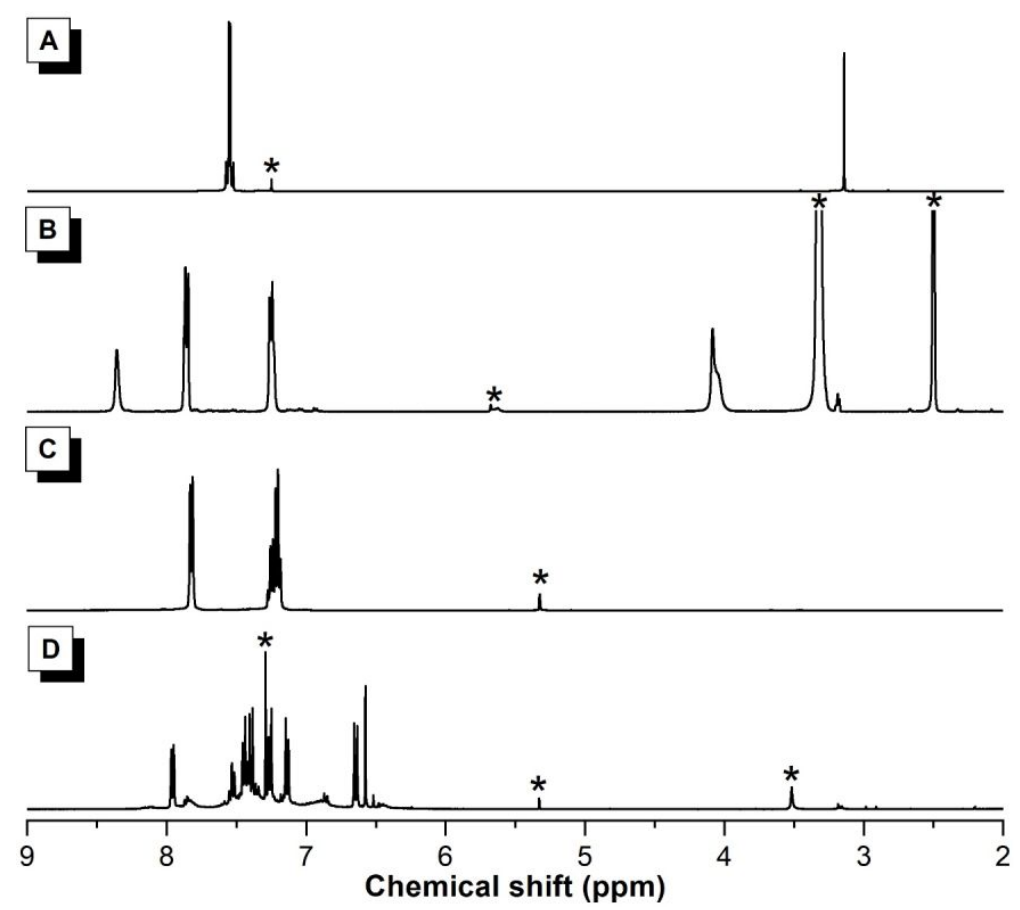

Figure S16. ${ }^{1} \mathrm{H}$ NMR spectra of (A) $1 \mathbf{b}$ and (D) P1b/2/3b in chloroform- $d$, (B) 2 in dimethyl sulfoxide- $d_{6}$, (C) 3b in dichloromethane- $d_{2}$. The solvent peaks were marked with asterisks. 


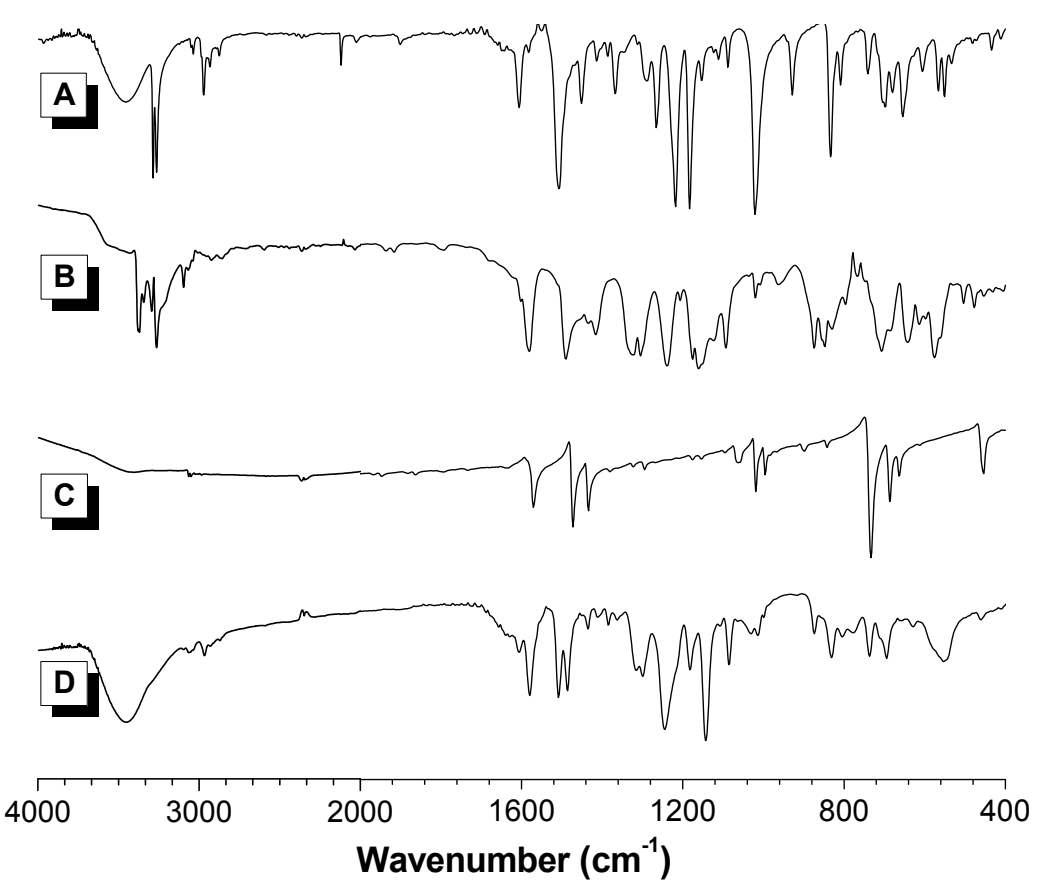

Figure S17. IR spectra of (A) 1c, (B) 2, (C) 3b and (D) P1c/2/3b.

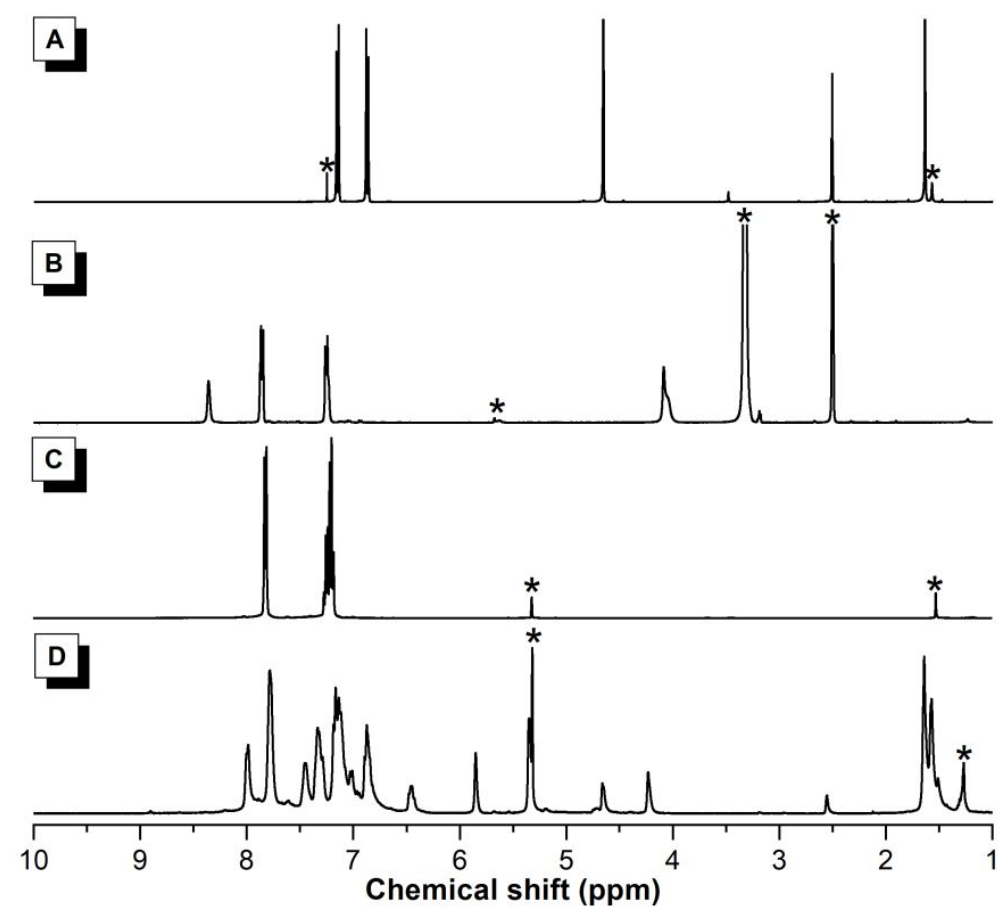

Figure S18. ${ }^{1} \mathrm{H}$ NMR spectra of (A) $1 \mathrm{c}$ in chloroform- $d$, (B) 2 in dimethyl sulfoxide$d_{6},(\mathrm{C}) \mathbf{3} \mathbf{b}$ and (D) P1c/2/3b in dichloromethane- $d_{2}$. The solvent peaks were marked with asterisks. 


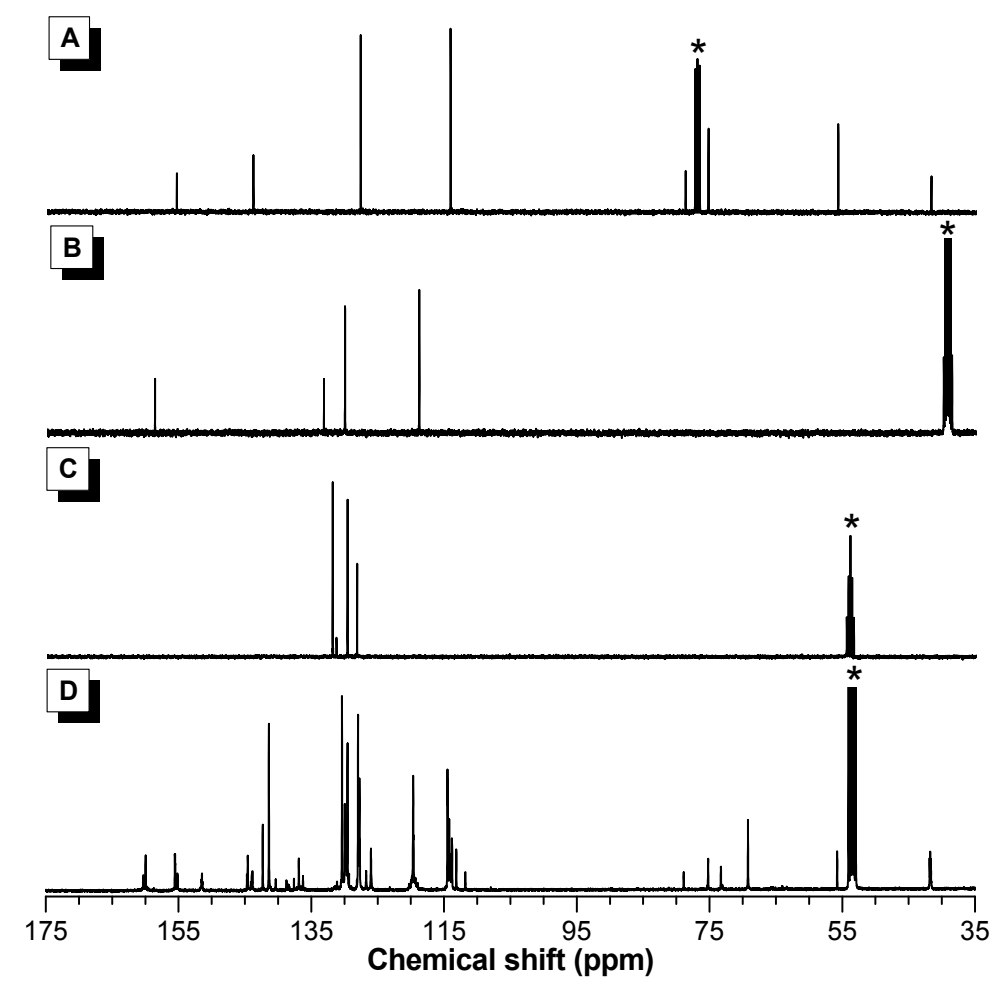

Figure S19. ${ }^{13} \mathrm{C}$ NMR spectra of (A) $1 \mathrm{c}$ in chloroform- $d$, (B) 2 in dimethyl sulfoxide$d_{6},(\mathrm{C}) \mathbf{3 b}$ and (D) P1c/2/3b in dichloromethane- $d_{2}$. The solvent peaks were marked with asterisks.

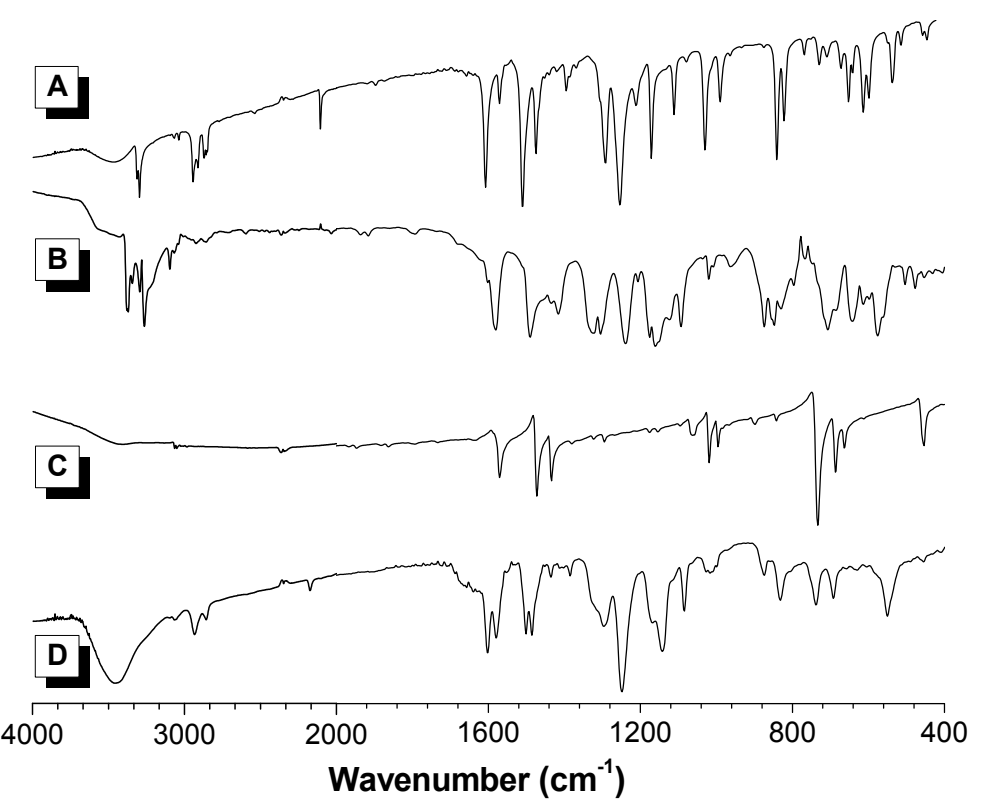

Figure S20. IR spectra of (A) 1d, (B) 2, (C) $\mathbf{3 b}$ and (D) P1d/2/3b. 


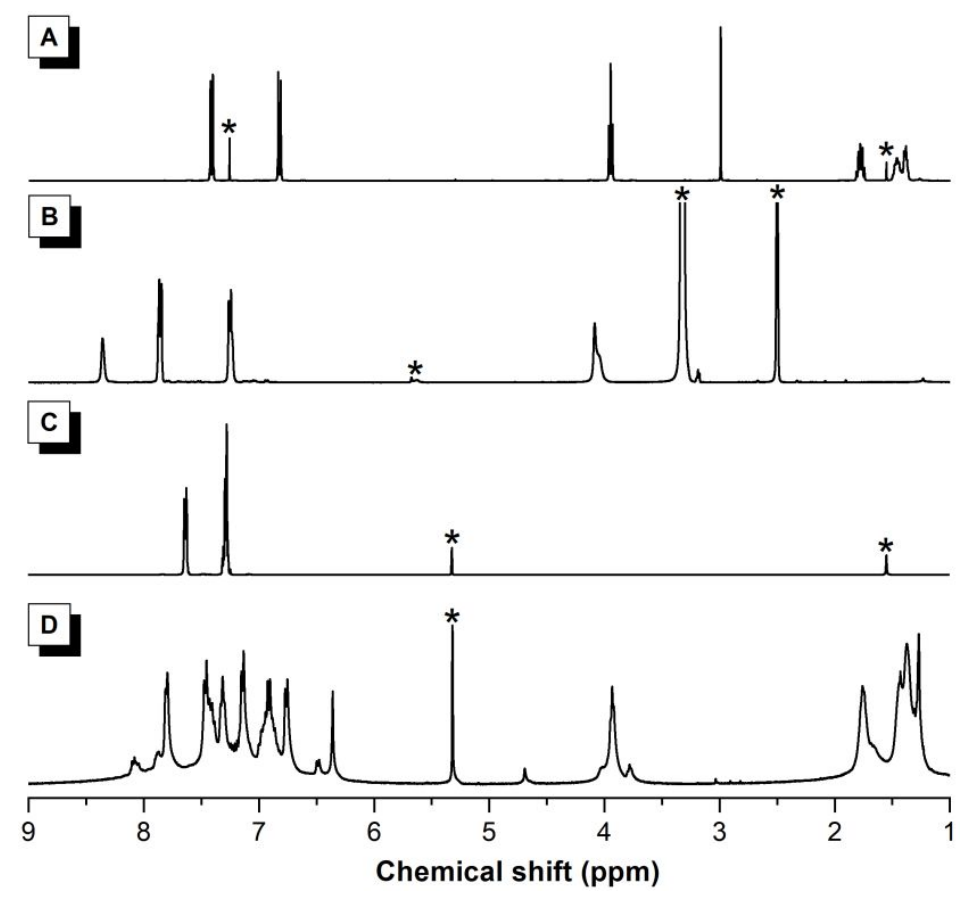

Figure S21. ${ }^{1} \mathrm{H}$ NMR spectra of (A) 1d in chloroform- $d$, (B) 2 in dimethyl sulfoxide$d_{6},(\mathrm{C}) \mathbf{3 b}$ and (D) P1d/2/3b in dichloromethane- $d_{2}$. The solvent peaks were marked with asterisks.

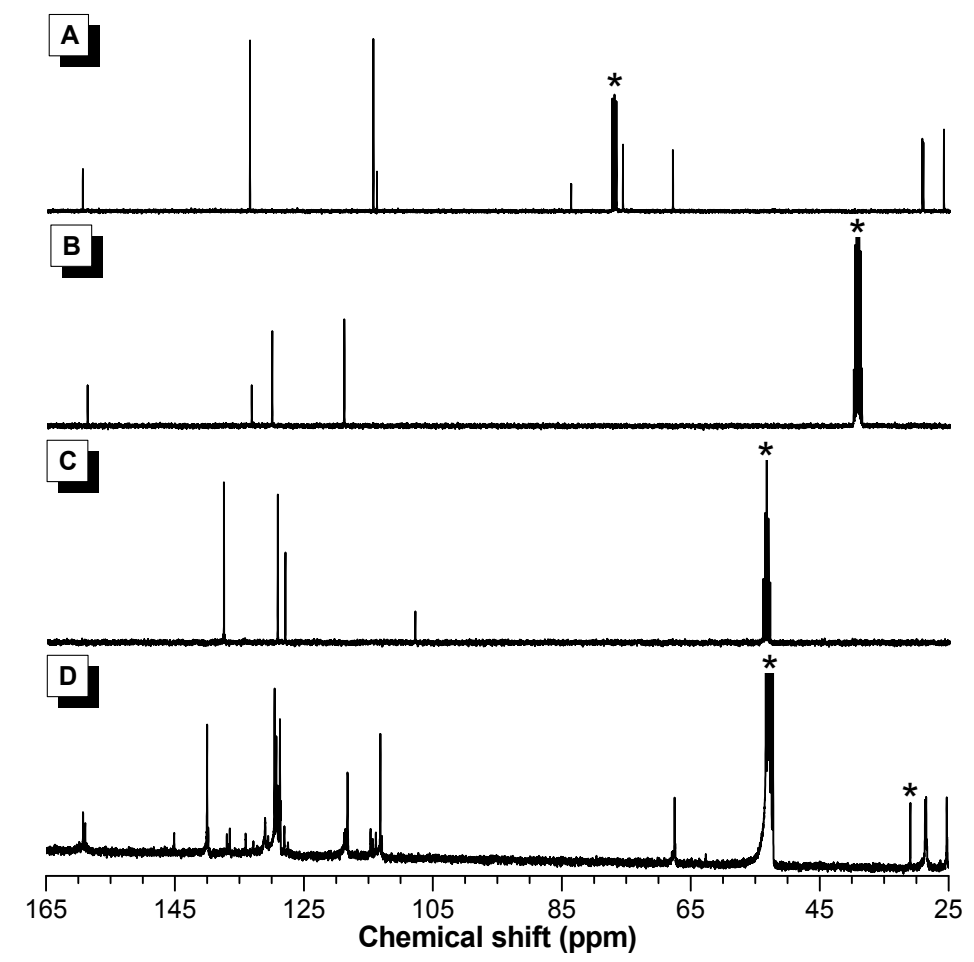

Figure S22. ${ }^{13} \mathrm{C}$ NMR spectra of (A) $1 \mathbf{d}$ in chloroform- $d$, (B) 2 in dimethyl sulfoxide$d_{6},(\mathrm{C}) \mathbf{3 b}$ and (D) P1d/2/3b in dichloromethane- $d_{2}$. The solvent peaks were marked with asterisks. 


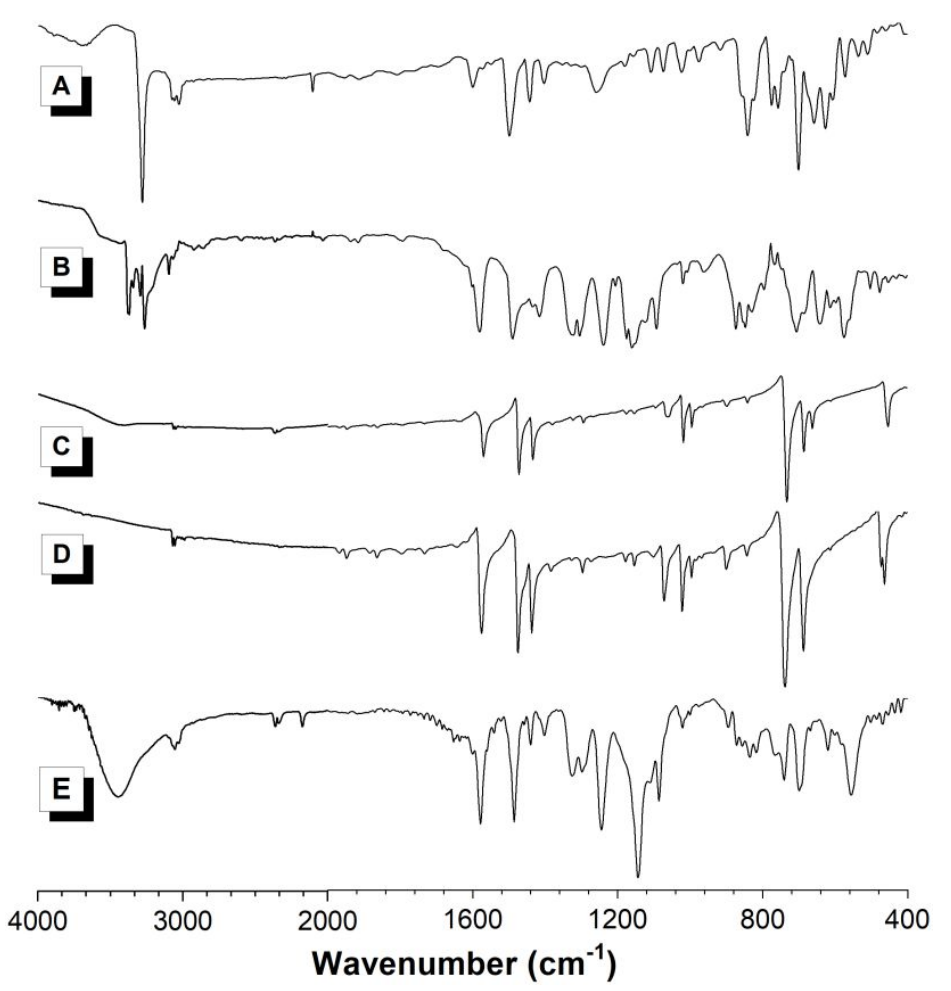

Figure S23. IR spectra of (A) 1a, (B) 2, (C) 3a, (D) 3c and (E) P1a/2/3ac.

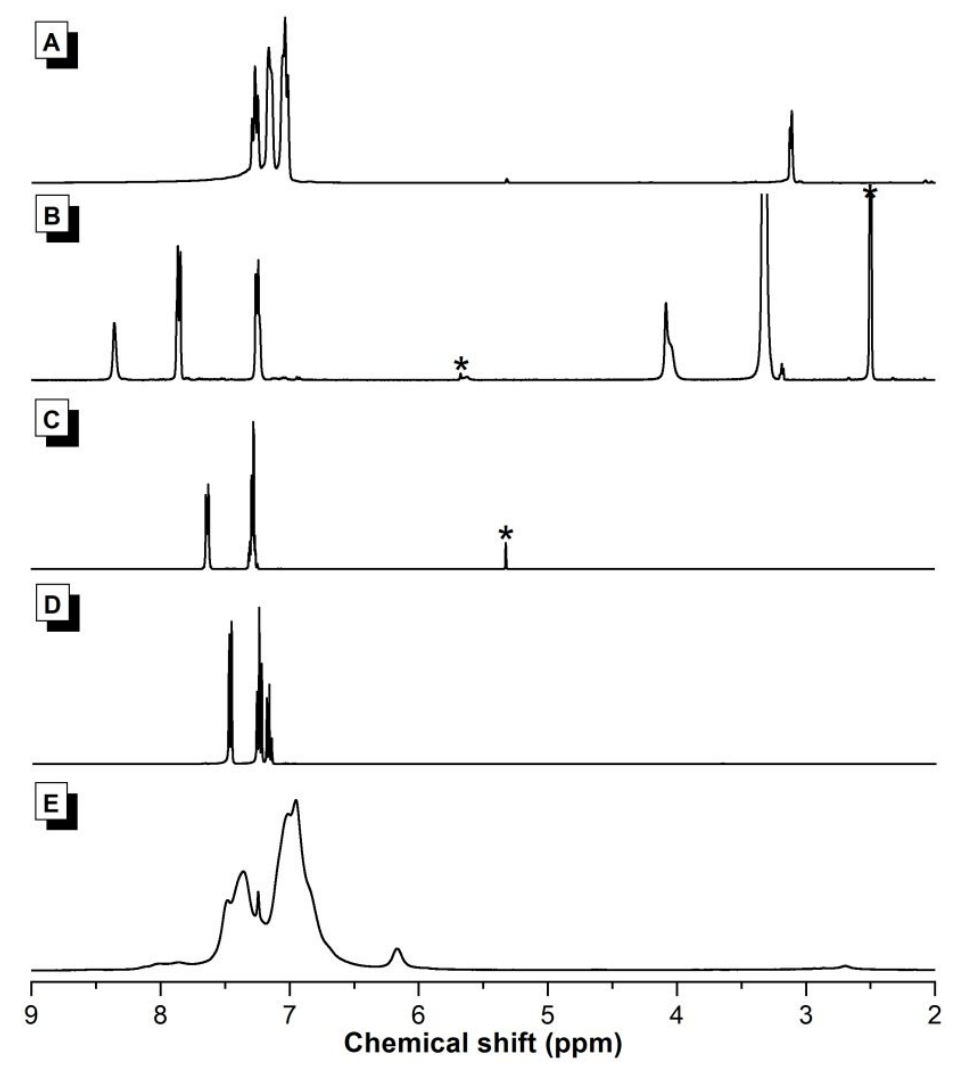

Figure S24. ${ }^{1} \mathrm{H}$ NMR spectra of (A) 1a and (C) 3a in dichloromethane- $d_{2}$, (B) 2 in dimethyl sulfoxide- $d_{6}$, (D) 3c and (E) P1a/2/3ac in chloroform- $d$. The solvent peaks were marked with asterisks. 


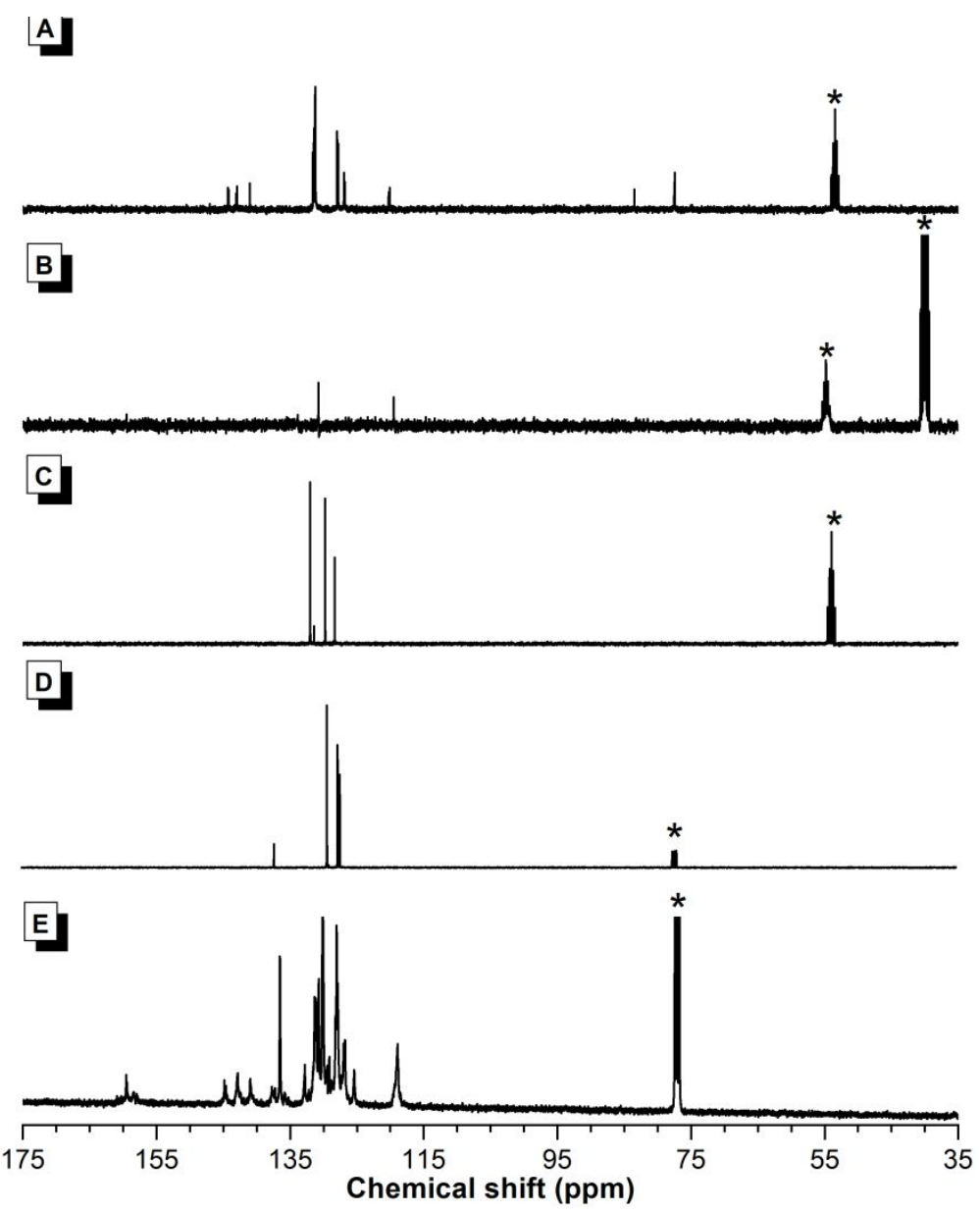

Figure S25. ${ }^{13} \mathrm{C}$ NMR spectra of (A) 1a and (C) 3a in dichloromethane- $d_{2}$, (B) 2 in dimethyl sulfoxide- $d_{6}$, (D) 3c and (E) P1a/2/3ac in chloroform- $d$. The solvent peaks were marked with asterisks.
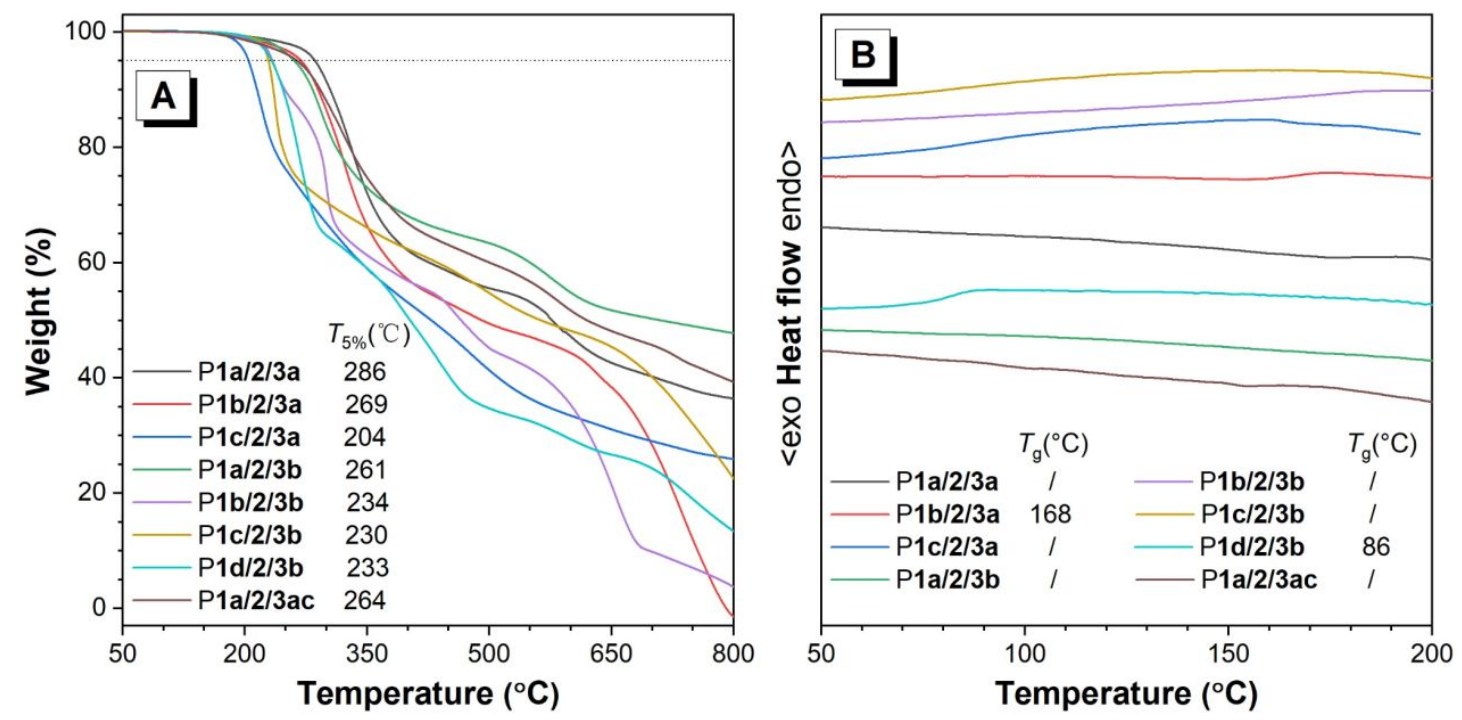

Figure S26. (A) TGA and (B) DSC thermograms of $\mathrm{P} \mathbf{1} / \mathbf{2} / \mathbf{3}$ recorded under nitrogen at a heating rate of $10^{\circ} \mathrm{C} / \mathrm{min}$. 

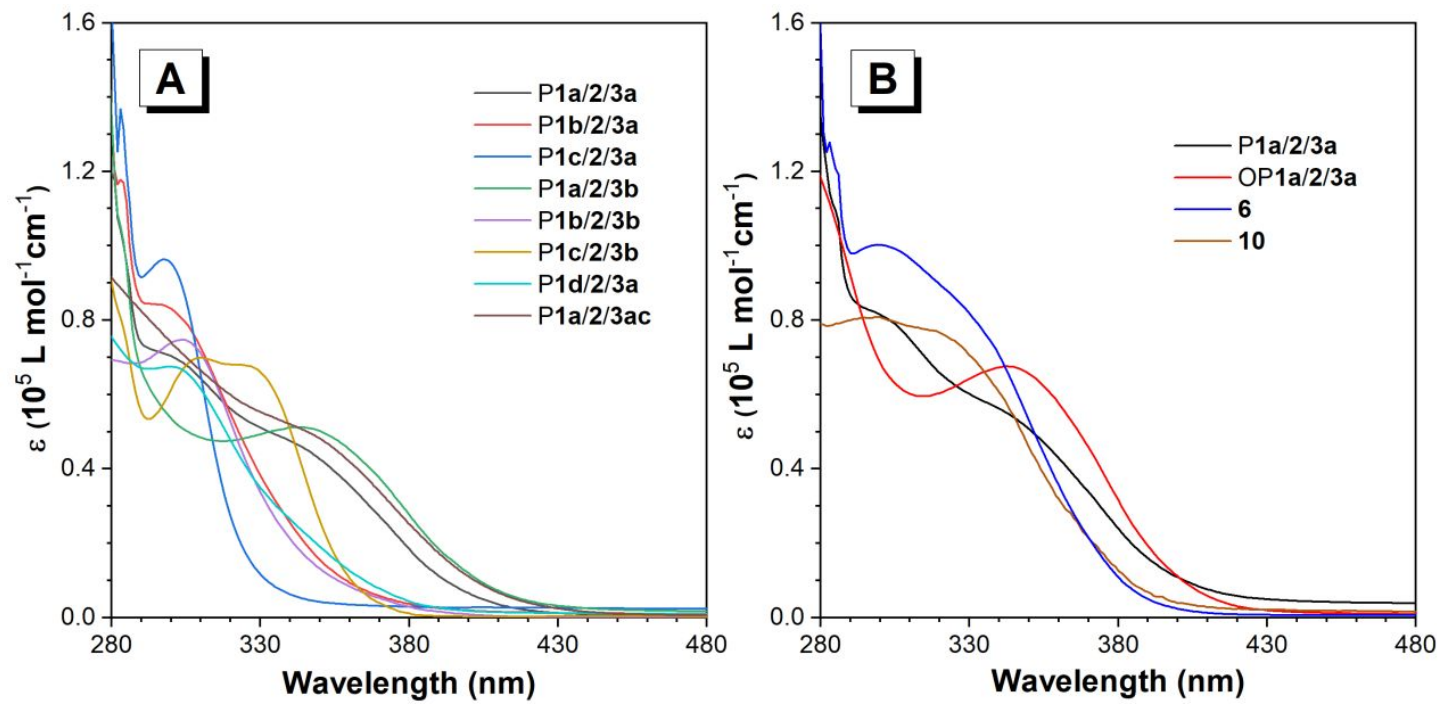

Figure S27. Absorption spectras of (A) P1/2/3 (B) and P1a/2/3a, OP1a/2/3a, 6 and 10 in THF solution. Solution concentration: $10 \mu \mathrm{M}$.
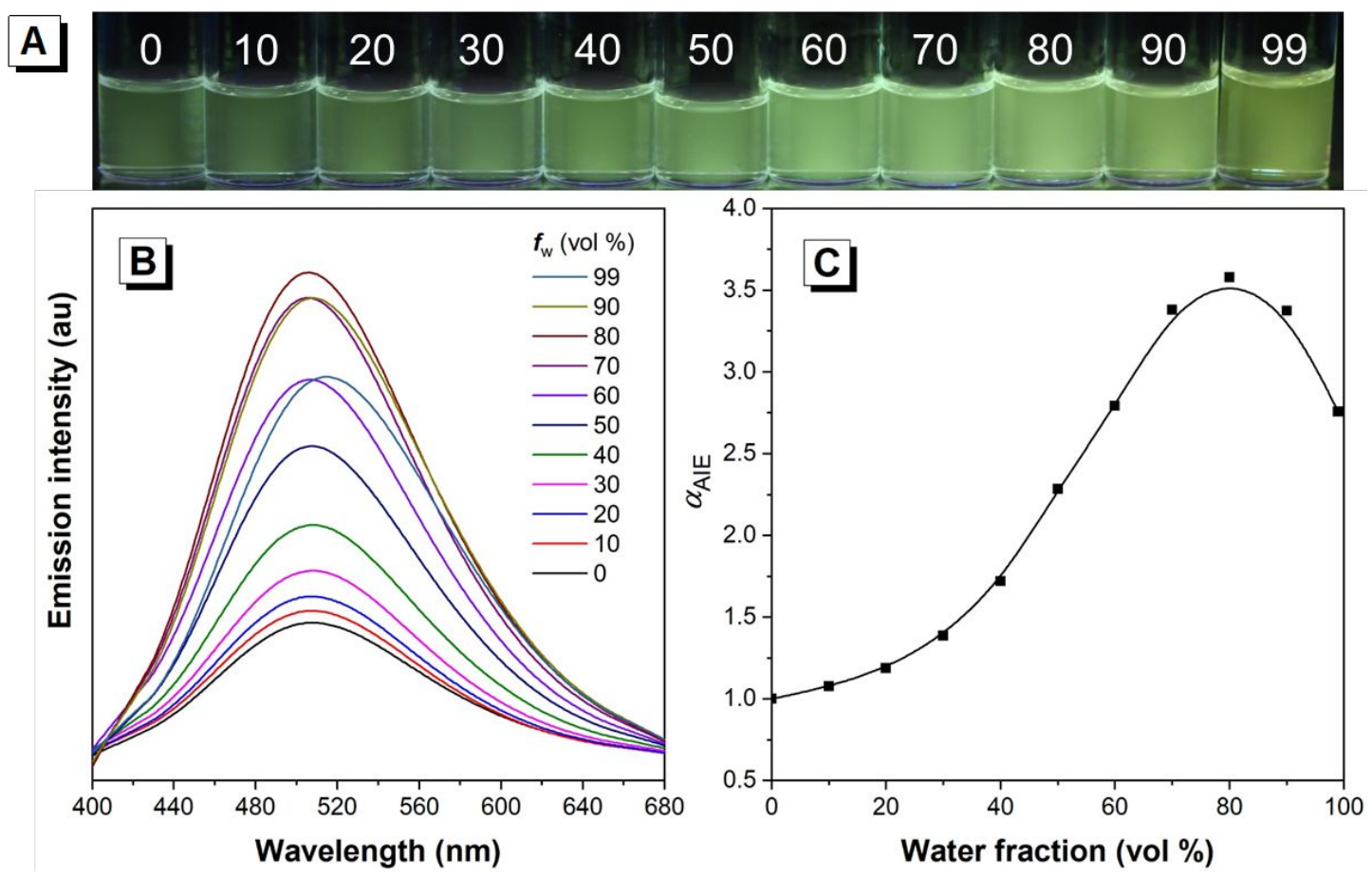

Figure S28. (A) Fluorescent photographs of P1a/2/3a in THF/water mixtures with different water fractions $\left(f_{w}\right)$ taken under $365 \mathrm{~nm}$ UV irradiation from a hand-held UV lamp. (B) The emission spectra of P1a/2/3a in $\mathrm{THF} /$ water mixtures with different water fractions $\left(f_{w}\right)$. Solution concentration: $10 \mu \mathrm{M}$; excitation wavelength: $350 \mathrm{~nm}$. (C) The plot of $\alpha_{\mathrm{AIE}}$ versus the water fraction of the THF/water mixtures of $\mathrm{P} \mathbf{1 a} / \mathbf{2} / \mathbf{3} \mathbf{a}$. 


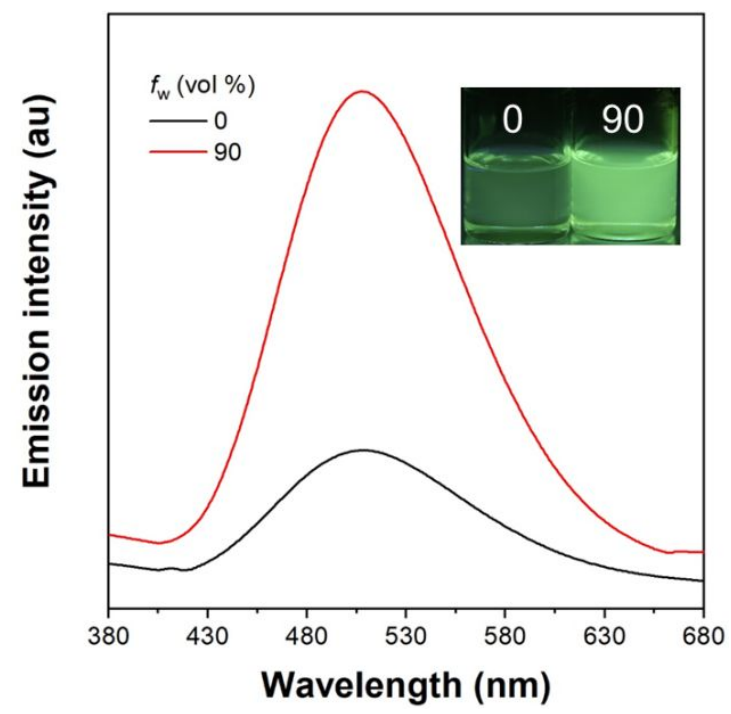

Figure S29. Emission spectra of $\mathrm{P} \mathbf{1 a} / \mathbf{2} / \mathbf{3 b}$ in THF solution and $\mathrm{THF} /$ water mixture with $90 \%$ water fraction. Solution concentration: $10 \mu \mathrm{M}$; excitation wavelength: 350 $\mathrm{nm}$. Inset: fluorescent photographs of $\mathrm{P} \mathbf{1 a} / \mathbf{2} / \mathbf{3 b}$ in THF solution and $\mathrm{THF} /$ water mixture with $90 \%$ water fraction taken under $365 \mathrm{~nm}$ UV illumination from a hand-held UV lamp.
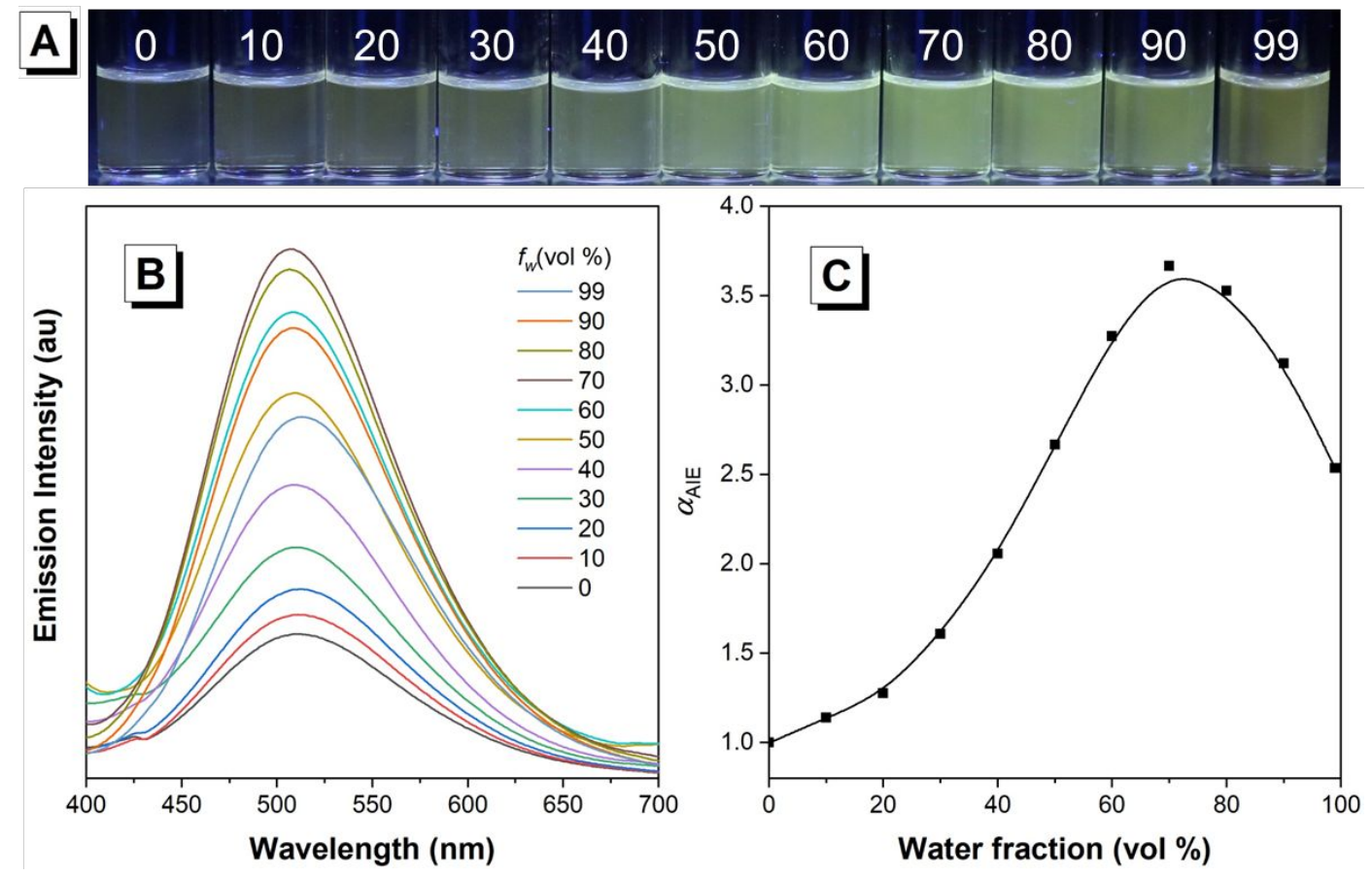

Figure S30. (A) Fluorescent photographs of P1a/2/3ac in $\mathrm{THF} /$ water mixtures with different water fractions $\left(f_{w}\right)$ taken under $365 \mathrm{~nm}$ UV irradiation from a hand-held UV lamp. (B) The emission spectra of P1a/2/3ac in THF/water mixtures with different water fractions $\left(f_{w}\right)$. Solution concentration: $10 \mu \mathrm{M}$; excitation wavelength: $350 \mathrm{~nm}$. (C) The plot of $\alpha_{\mathrm{AIE}}$ versus the water fraction of the THF/water mixtures of P1a/2/3ac. 

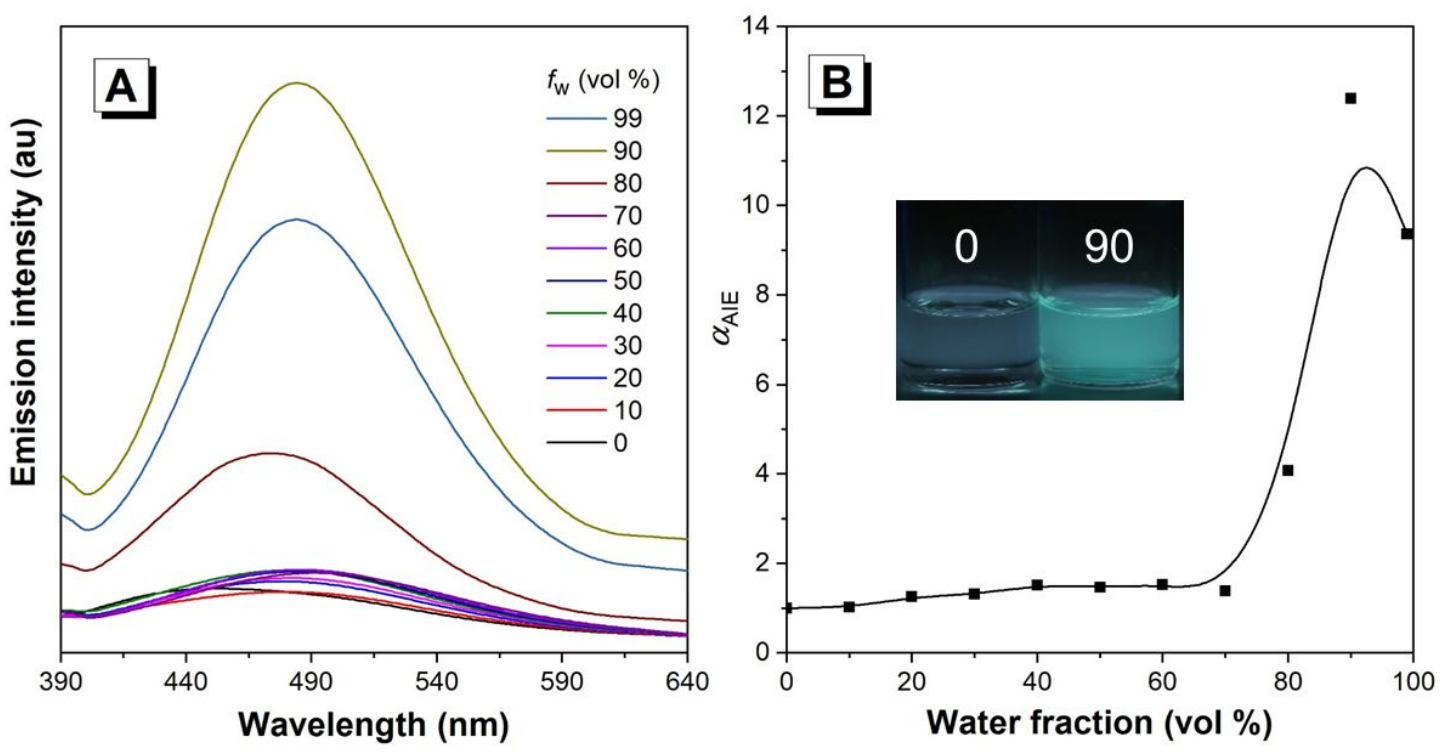

Figure S31. (A) Emission spectra of model compound 6 in THF/water mixtures with different water fractions $\left(f_{w}\right)$. Solution concentration: $10 \mu \mathrm{M}$; excitation wavelength: $330 \mathrm{~nm}$. (B) The plot of $\alpha_{\mathrm{AIE}}$ versus the water fraction of the THF/water mixtures of 6. Inset: fluorescent photographs of 6 in THF solution and THF/water mixture with $90 \%$ water fraction taken under $365 \mathrm{~nm}$ UV illumination from a hand-held UV lamp.
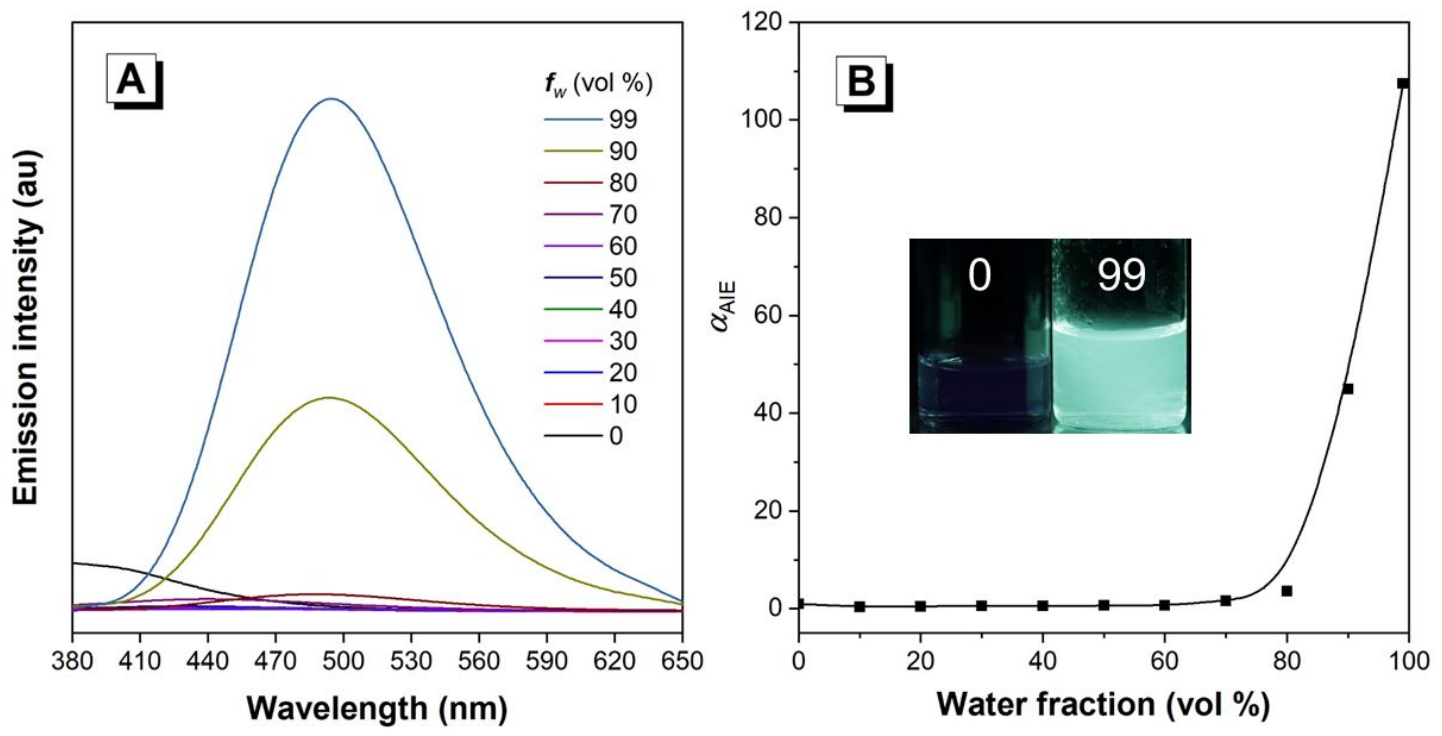

Figure S32. Emission spectra of $\mathbf{1 0}$ in THF/water mixtures with different water fractions $\left(f_{w}\right)$. Solution concentration: $10 \mu \mathrm{M}$; excitation wavelength: $330 \mathrm{~nm}$. (B) The plot of $\alpha_{\mathrm{AIE}}$ versus the water fraction of the THF/water mixtures of 10. Inset: fluorescent photographs of 10 in THF solution and THF/water mixture with 99\% water fraction taken under $365 \mathrm{~nm}$ UV illumination from a hand-held UV lamp. 

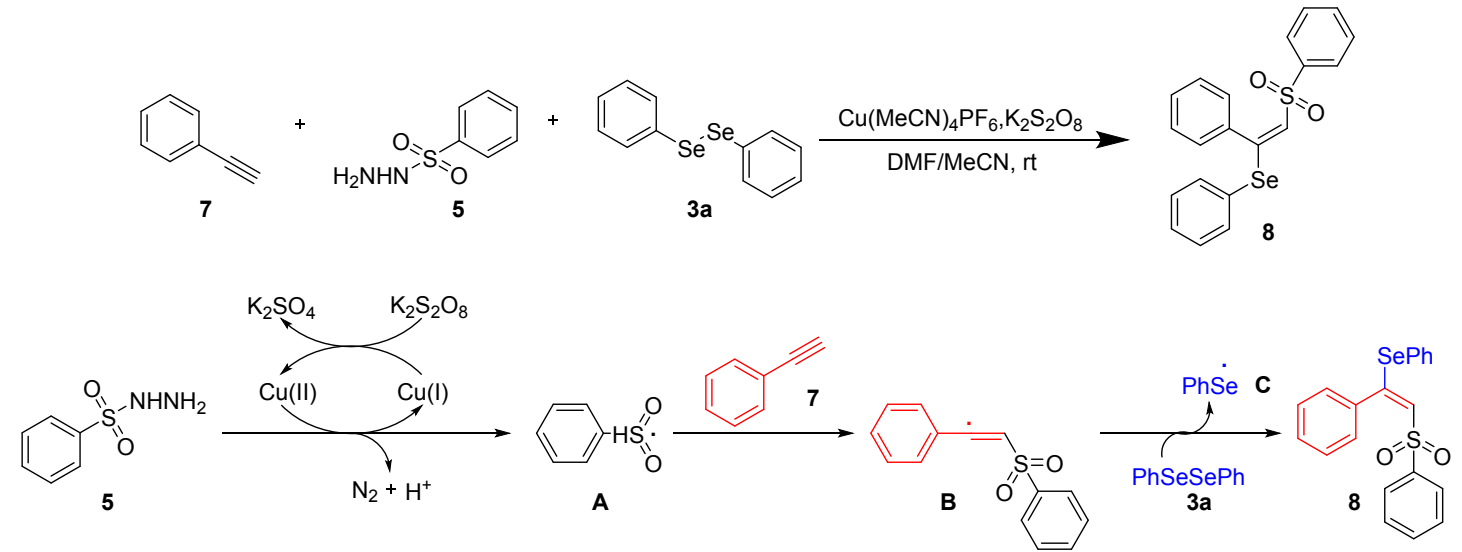

Figure S33. Mechanism of copper-catalyzed reaction of diphenyl diselenide, benzenesulfonyl hydrazide and terminal alkyne.

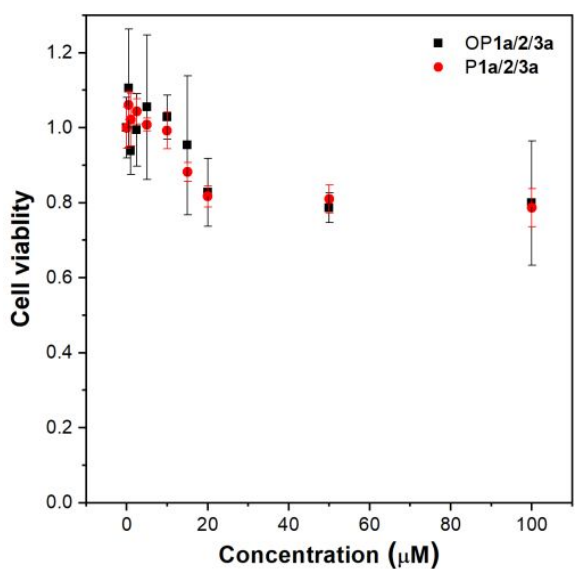

Figure S34. MTT assay on HeLa cells incubated with P1a/2/3a and OP1a/2/3a at different concentrations from 0 to $100 \mu \mathrm{M}$ for $24 \mathrm{~h}$.

Table S8. Quantum yields of polymers solids.

\begin{tabular}{lc}
\hline polymer & quantum yield (\%) \\
\hline $\mathrm{P} 1 \mathbf{a} / \mathbf{2} / \mathbf{3 a}$ & 2.7 \\
$\mathrm{P} \mathbf{1 a} / \mathbf{2} / \mathbf{3 b}$ & 5.8 \\
$\mathrm{P} \mathbf{1 a} / \mathbf{2} / \mathbf{3 a c}$ & 1.9 \\
$\mathrm{OP} \mathbf{1 a} / \mathbf{2} / \mathbf{3 a}$ & 13.4 \\
\hline
\end{tabular}




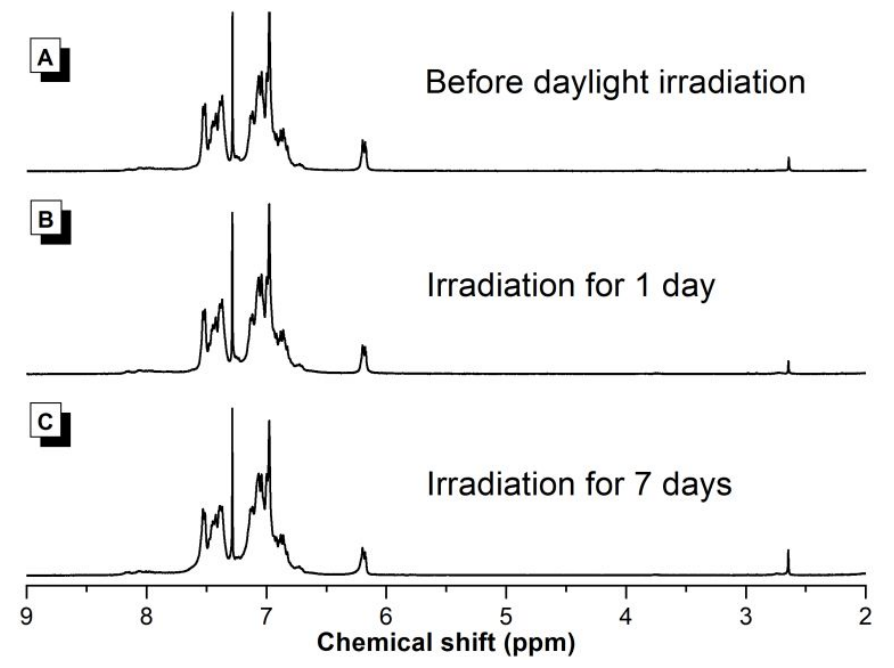

Figure S35. ${ }^{1} \mathrm{H}$ NMR spectra of the P1a/2a/3a before and after light irradiation.

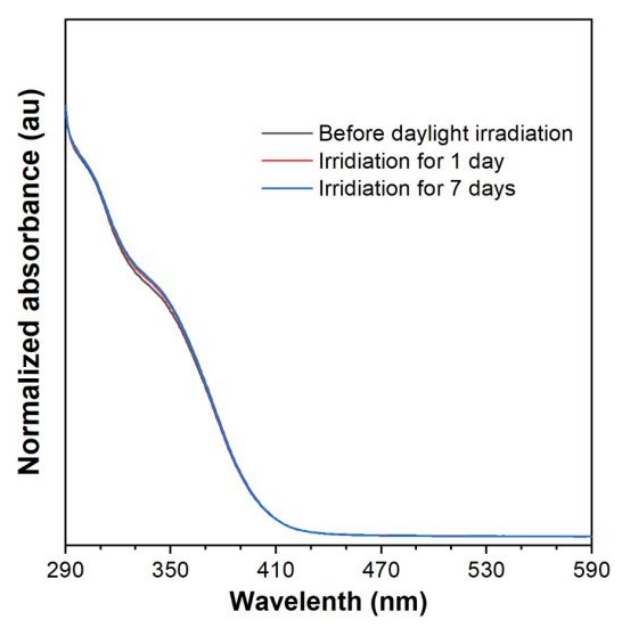

Figure S36. UV spectra of the THF solutions of P1a/2/3a before and after light irradiation.

\section{Reference}

(1) Hu, R.; Lam, J. W. Y.; Liu, J.; Sung, H. H. Y.; Williams, I. D.; Yue, Z.; Wong, K. S.; Yuen, M. M. F.; Tang, B. Z. Polym. Chem. 2012, 3, 1481-1489.

(2) Limberg, F. R. P.; Miasojedovas, A.; Pingel, P.; Reisbeck, F.; Janietz, S.; Monkman, A. P.; Krüger, H. RSC Advances 2015, 5, 83122-83128.

(3) Qiu, Z.; Han, T.; Kwok, R. T. K.; Lam, J. W. Y.; Tang, B. Z. Macromolecules 2016, 49, 8888-8898. 